\title{
Net currents in the wave bottom boundary layer: On waveshape streaming and progressive wave streaming
}

\author{
Wouter M. Kranenburg, ${ }^{1}$ Jan S. Ribberink, ${ }^{1}$ Rob E. Uittenbogaard, ${ }^{2}$ \\ and Suzanne J. M. H. Hulscher ${ }^{1}$ \\ Received 26 April 2011; revised 15 May 2012; accepted 16 May 2012; published 17 July 2012.
}

[1] The net current (streaming) in a turbulent bottom boundary layer under waves above a flat bed, identified as potentially relevant for sediment transport, is mainly determined by two competing mechanisms: an onshore streaming resulting from the horizontal non-uniformity of the velocity field under progressive free surface waves, and an offshore streaming related to the nonlinearity of the waveshape. The latter actually contains two contributions: oscillatory velocities under nonlinear waves are characterized in terms of velocity-skewness and acceleration-skewness (with pure velocity-skewness under Stokes waves and acceleration-skewness under steep sawtooth waves), and both separately induce offshore streaming. This paper describes a 1DV Reynolds-averaged boundary layer model with $k-\varepsilon$ turbulence closure that includes all these streaming processes. The model is validated against measured period-averaged and time-dependent velocities, from 4 different well-documented laboratory experiments with these processes in isolation and in combination. Subsequently, the model is applied in a numerical study on the waveshape and free surface effects on streaming. The results show how the dimensionless parameters $k h$ (relative water depth) and $A / k_{\mathrm{N}}$ (relative bed roughness) influence the (dimensionless) streaming velocity and shear stress and the balance between the mechanisms. For decreasing $k h$, the relative importance of waveshape streaming over progressive wave streaming increases, qualitatively consistent with earlier analytical modeling. Unlike earlier results, simulations for increased roughness (smaller $A / k_{\mathrm{N}}$ ) show a shift of the streaming profile in onshore direction for all $k h$. Finally, the results are parameterized and the possible implications of the streaming processes on sediment transport are shortly discussed.

Citation: Kranenburg, W. M., J. S. Ribberink, R. E. Uittenbogaard, and S. J. M. H. Hulscher (2012), Net currents in the wave bottom boundary layer: On waveshape streaming and progressive wave streaming, J. Geophys. Res., 117, F03005, doi:10.1029/ 2011JF002070.

\section{Introduction}

[2] The dynamics of water and sediment in the bottom boundary layer under waves in coastal seas are of key importance for the development of cross-shore and longshore coastal profiles. Many recent studies on the complex interaction between wave motion and seabed emphasize the influence of the waveshape on bed shear stress, sediment transport and flow velocities, either focusing on velocityskewness (present under waves with amplified crests), acceleration-skewness (present under waves with steep

\footnotetext{
${ }^{1}$ Water Engineering \& Management, University of Twente, Enschede, Netherlands.

${ }^{2}$ Deltares, Delft, Netherlands.

Corresponding author: W. M. Kranenburg, Water Engineering \& Management, University of Twente, Box 217, NL-7500 AE Enschede, Netherlands. (w.m.kranenburg@utwente.nl)

C2012. American Geophysical Union. All Rights Reserved. 0148-0227/12/2011JF002070
}

fronts) or both phenomena in joint occurrence (for references see Ruessink et al. [2009]). Experimental studies on waveshape effects have often been carried out in oscillating flow tunnels, with both fixed and mobile beds of various sand grain sizes, and special attention has been paid to the sheet-flow transport regime, where bed forms are washed away and the bed is turned into a moving sediment layer [Ribberink et al., 2008]. An important observation from tunnel experiments in the sheet-flow regime is that under velocity-skewed flow over coarse grains the sediment transport is mainly onshore, but that net transport decreases with decreasing grain sizes and can even become negative for fine sand [O'Donoghue and Wright, 2004]. DohmenJanssen and Hanes [2002] and very recently Schretlen et al. [2011] carried out detailed full-scale wave flume experiments on sand transport by waves in the sheet-flow regime. These flume measurements show onshore instead of offshore transport of fine sand under 2nd order Stokes waves and larger transport rates for medium-sized sand compared to experiments with comparable velocity-skewness in oscillating flow 
tunnels. These different results for sediment transport emphasize the importance of a good understanding of the hydrodynamic differences between oscillating flow tunnels, with horizontally uniform oscillating pressure gradients, and wave flumes, with horizontally non-uniform pressure gradients and vertical motions due to the free surface.

[3] A remarkable free surface effect that potentially contributes to onshore (current related) sediment transport is the generation of a steady bottom boundary layer current in onshore direction [Longuet-Higgins, 1953]: the vicinity of the bed affects the phase of the horizontal and vertical orbital velocities. This introduces a wave-averaged downward transport of horizontal momentum that drives an onshore boundary layer current (here called 'progressive wave streaming'). This process acts opposite to the net current that will be generated in a turbulent bottom boundary layer by a velocity-skewed or acceleration-skewed oscillation ('waveshape streaming'). The latter mechanism, that can be present both in tunnels and flumes, is due to the different characteristics of the time-dependent turbulence during the on- and offshore phase of the wave, introducing a nonzero wave-averaged turbulent shear stress. This phenomenon was first predicted for velocity-skewed waves by Trowbridge and Madsen [1984b] and observed in tunnel experiments by Ribberink and Al-Salem [1995].

[4] It is the aim of this study to develop a carefully validated numerical model for the net currents in the turbulent wave boundary layer above a flat but hydraulically rough bed, and to develop more insights in the balance between the waveshape streaming and progressive wave streaming on the shoreface.

[5] The various streaming contributions have been modeled before by several authors: Longuet-Higgins [1958] predicted the onshore streaming under progressive waves analytically using a constant viscosity. Johns [1970] included height-dependency in the eddy viscosity and later Johns [1977] used a turbulent kinetic energy closure in a numerical study on the residual flow under linear waves. Trowbridge and Madsen [1984a] developed an analytical model with time dependent eddy viscosity. Their second order approach [Trowbridge and Madsen, 1984b] (TM84) jointly included 1) the advective terms of the momentum equation, 2) (forcing) free stream velocities determined with Stokes' 2nd order wave theory, and 3) an eddy viscosity being the product of a vertical length scale and the first three Fourier components of the shear velocity. This key development revealed the competition between onshore progressive wave streaming and offshore velocity-skewness streaming, with dominance of the latter for relatively long waves. Later work [Trowbridge and Young, 1989] and a recent coupling of the TM84 model with a bed load transport formula [Gonzalez Rodriquez, 2009, chapter 6] indeed showed a significant effect of progressive wave streaming on shear stress and net bed load transport. Due to the absence of detailed flume measurements and just tunnel data available for validation, progressive wave streaming was not included in most of the (one and two phase) numerical boundary layer models developed for research on shear stress and sediment transport under waves [e.g., Davies and Li, 1997; Holmedal and Myrhaug, 2006; Conley et al., 2008; Fuhrman et al., 2009a, 2009b; Hassan and Ribberink, 2010; Hsu and Hanes, 2004; Li et al., 2008; Ruessink et al., 2009]. Such models, both with one and two-equation ( $k-\varepsilon$ and $k-\omega)$ turbulence closures, are generally fairly well capable to reproduce the velocityskewness streaming as measured in tunnels by Ribberink and Al-Salem [1995]. These Reynolds-averaged models have recently been supported by results of Direct Numerical Simulations [Cavallaro et al., 2011], have been used in a 2D version to investigate slope effects in tunnels [Fuhrman et al., 2009a] and have shown good reproduction of measured sediment transport rates in tunnels as well [e.g., Ruessink et al., 2009; Hassan and Ribberink, 2010].

[6] To the author's knowledge, only a few studies [Henderson et al., 2004; Hsu et al., 2006; Holmedal and Myrhaug, 2009; Yu et al., 2010] have presented numerical boundary layer models that include effects of the free surface and the waveshape on the boundary layer flow simultaneously. These studies demonstrate respectively the relevance of progressive wave streaming for onshore sandbar migration (first two references, validation on morphological field data), for streaming profile predictions (third reference, without data-model comparison) and for suspended sediment transport (fourth reference, validation on concentration profiles). Nevertheless, a detailed validation of the numerical models on net current measurements is still lacking until now.

[7] Considering the experimental observations and indications from the model studies, the research objectives in this study are: i) to validate the hydrodynamics of a numerical Reynolds-averaged boundary layer model, extended with free surface effects, using selected laboratory measurements of different types of wave boundary layer flow, ii) to apply this model to obtain insight in the balance between progressive wave streaming and waveshape streaming, and how this is affected by varying wave and bed conditions. Our model, basically an extension of the model used in Ruessink et al. [2009] and Hassan and Ribberink [2010], is described in section 2. The model validation on detailed velocity measurements above fixed beds is given in section 3 . The balance between progressive wave streaming and velocity-skewness streaming is studied with a systematic numerical investigation of velocities and shear stresses in section 4. Section 5 gives a short outlook on the implications of modeling these streaming processes on sediment transport predictions. Section 6 summarizes the major conclusions of this study.

\section{Model Formulation}

\subsection{Equations Describing the Wave Boundary Layer}

[8] This study considers the water motion under waves close to the bed to determine the net, period averaged current. The short period of the horizontal oscillation confines the generation of time-dependent turbulence to a layer that is thin compared to the wavelength. Therefore, the boundary layer approximation is applied and the flow field is described with a Reynolds-averaged momentum equation and a continuity equation:

$$
\begin{gathered}
\frac{\partial u}{\partial t}+u \frac{\partial u}{\partial x}+w \frac{\partial u}{\partial z}=-\frac{1}{\rho} \frac{\partial p}{\partial x}+\frac{\partial}{\partial z}\left\{\left(v+v_{t}\right) \frac{\partial u}{\partial z}\right\} \\
\frac{\partial u}{\partial x}+\frac{\partial w}{\partial z}=0
\end{gathered}
$$


where $u$ is the horizontal velocity, $w$ the vertical velocity, $\rho$ the density of water, $p$ the pressure, $v$ the kinematic viscosity of water, $v_{\mathrm{t}}$ the turbulent viscosity, $t$ the time and $x$ and $z$ horizontal and vertical axes directed respectively onshore and upward. Within the boundary layer, the horizontal pressure gradient is approximately constant over the vertical.

[9] A $k-\varepsilon$ model [Launder and Spalding, 1972; Rodi, 1984] provides the closure for $v_{\mathrm{t}}$ :

$$
\begin{gathered}
v_{t}=c_{\mu} \frac{k^{2}}{\varepsilon} \\
\frac{\partial k}{\partial t}+u \frac{\partial k}{\partial x}+w \frac{\partial k}{\partial z}=\frac{\partial}{\partial z}\left\{\left(v+\frac{v_{t}}{\sigma_{k}}\right) \frac{\partial k}{\partial z}\right\}+P_{k}-\varepsilon \\
\frac{\partial \varepsilon}{\partial t}+u \frac{\partial \varepsilon}{\partial x}+w \frac{\partial \varepsilon}{\partial z}=\frac{\partial}{\partial z}\left\{\left(v+\frac{v_{t}}{\sigma_{\varepsilon}}\right) \frac{\partial \varepsilon}{\partial z}\right\}+\frac{\varepsilon}{k}\left(c_{1 \varepsilon} P_{k}-c_{2 \varepsilon} \varepsilon\right)
\end{gathered}
$$

where $k$ is the turbulent kinetic energy, $P_{\mathrm{k}}$ is the turbulence production, $\varepsilon$ is the dissipation rate, and $\sigma_{\mathrm{k},} \sigma_{\varepsilon}, c_{\mu}, \mathrm{c}_{1 \varepsilon}$ and $c_{2 \varepsilon}$ are constants, respectively $1.0,1.3,0.09,1.44,1.92$ (standard values), [Rodi, 1984]. The production term yields:

$$
P_{k}=v_{t}\left(\frac{\partial u}{\partial z}\right)^{2}
$$

because it follows from the boundary layer assumption that the contribution by vertical shear can be neglected. (Note that also sediment-induced stratification effects are not considered in the present hydrodynamic study).

\subsection{Forcing}

[10] Two alternatives have been formulated to force the model. In the first alternative, here called the 'match' model, the principally unknown $u(z)$ is forced to match a predefined horizontal velocity signal at a certain vertical level $z_{\mathrm{m}}$. This level may be in, or a limited distance above, the wave boundary layer and the signal could have a nonzero mean. The associated pressure gradient is determined automatically by the model. In the second alternative, the 'free' model formulation, the unsteady horizontal pressure gradient $\widetilde{p}$ is determined in advance from a given horizontal (component of a) free stream velocity $\tilde{u}_{\infty}$ with zero mean using:

$$
-\frac{1}{\rho} \frac{\partial \widetilde{p}}{\partial x}=\frac{\partial \widetilde{u}_{\infty}}{\partial t}+\widetilde{u}_{\infty} \frac{\partial \widetilde{u}_{\infty}}{\partial x}
$$

In this approach the net current arising from the streaming mechanisms is not compensated by any mean pressure gradient and is allowed to develop freely. The first alternative is especially suitable to compare the model with measurements that, by their nature, not only include boundary layer streaming mechanisms, but also possible return currents. The mere balance between boundary layer streaming mechanisms can be investigated using the second forcing alternative, adopting any temporal velocity series to predefine $\tilde{u}_{\infty}$, e.g., from 2 nd order Stokes theory (as applied by Trowbridge and Madsen [1984b] and Holmedal and Myrhaug [2009]). Second order Stokes theory gives:

$$
\begin{aligned}
& \hat{u}_{1, \infty}=\frac{\omega}{k} \frac{a k}{\sinh (k h)} \quad ; \quad \hat{u}_{2, \infty}=\hat{u}_{1, \infty} \frac{3}{4} \frac{a k}{\sinh ^{3}(k h)} ; \\
& \tilde{u}_{\infty}(t)=\sum_{n=1}^{2} \hat{u}_{n, \infty} \cos (n \omega t)
\end{aligned}
$$

with $\hat{u}_{\mathrm{n}, \infty}$ the amplitude of the $\mathrm{n}$-th harmonic component of $\tilde{u}_{\infty}, h$ the water depth and $k, a$ and $\omega$ respectively the wave number, amplitude and angular frequency.

\subsection{DV-Approach}

[11] If time- and length scale of changes in the waveshape are large compared to wave period and length, the wave can be considered as a sum of steady harmonic oscillations with identical phase speed. This allows for a $1 \mathrm{DV}$-approach by transforming horizontal velocity gradients into time derivatives [Trowbridge and Madsen, 1984b] with:

$$
\frac{\partial u}{\partial x}=-\frac{1}{c} \frac{\partial u}{\partial t}
$$

where $c$ is the wave celerity determined from water depth $h$ and wave period $T$ through the regular dispersion relation. Using transformation (9) and continuity equation (2) the vertical velocity at level $z$ can be expressed as:

$$
w(z)=\frac{1}{c} \int_{0}^{z} \frac{\partial u}{\partial t} d z
$$

\subsection{Boundary Conditions}

[12] To solve equations (1), (4) and (5) using the 1DVapproach, six boundary conditions are needed. In the present model, the lower boundary $(z=0)$ is defined at the top of the roughness elements and turbulent flow over a hydraulically rough bed is modeled with a partial slip condition. Making use of an assumed logarithmic velocity profile close to the bed, the quadratic friction law, and local equilibrium between production and dissipation:

$$
\frac{u(z)}{u *}=\frac{1}{\kappa} \ln \left(\alpha+\frac{z}{z_{0}}\right) ; \quad u_{*}^{2}=\left.\left(v_{t} \frac{\partial u}{\partial z}\right)\right|_{z=0} \quad ;\left.\quad P_{k}\right|_{z=0}=\left.\varepsilon\right|_{z=0}
$$

the lower boundary conditions are:

$$
\left.\frac{\partial u}{\partial z}\right|_{z=0}=\frac{u_{*}}{\alpha \kappa z_{0}} \quad ;\left.\quad k\right|_{z=0}=\frac{u_{*}^{2}}{\sqrt{c_{\mu}}} \quad ;\left.\quad \varepsilon\right|_{z=0}=\frac{u_{*}^{3}}{\alpha \kappa z_{0}}
$$

Where $u_{*}$ is the friction velocity, $\kappa$ is the Von Karman constant, 0.41, and $z_{0}$ is the roughness length scale for hydraulically rough flow related to the Nikuradse roughness height $k_{\mathrm{N}}$ with $z_{0}=k_{\mathrm{N}} / 30$. With $\mathrm{z}=0$ defined at the top of the roughness elements, a value $\alpha \neq 1$ has to be adopted. Here, $\alpha=9$ is used based on Hinze [1975] and Jackson [1981].

[13] In the free model formulation, no wave-averaged pressure gradient resulting from a mean surface slope caused 
Table 1. Summary of Model Characteristics and Type of Validation for the Various Model Versions, Compared With Boundary Layer Models in Recent Literature

\begin{tabular}{|c|c|c|c|c|c|c|c|c|c|}
\hline & BL1-Match & BL1-Free & BL2- Match & BL2-Free & $\begin{array}{c}\text { Ruessink } \\
\text { et al. [2009] }\end{array}$ & $\begin{array}{c}\text { Hassan and } \\
\text { Ribberink } \\
\text { [2010] }\end{array}$ & $\begin{array}{l}\text { Fuhrman } \\
\text { et al. } \\
\text { [2009a] }\end{array}$ & $\begin{array}{c}\text { Holmedal and } \\
\text { Myrhaug } \\
{[2009]}\end{array}$ & $\begin{array}{r}\text { Henderson } \\
\text { et al. }[2004\end{array}$ \\
\hline \multicolumn{10}{|l|}{ Equations } \\
\hline Advective terms included? & $\mathrm{N}$ & $\mathrm{N}$ & $\mathrm{Y}$ & Y & $\mathrm{N}$ & $\mathrm{N}$ & $\mathrm{N}$ & $\mathrm{Y}$ & $\mathrm{Y}$ \\
\hline \multicolumn{10}{|l|}{ Forcing } \\
\hline $\begin{array}{l}\text { Measured velocity signal (1) } \\
\text { or oscillating free stream } \\
\text { velocity }(2) ?\end{array}$ & 1 & 2 & 1 & 2 & 1 & 1 & 1 & 2 & 1 \\
\hline \multicolumn{10}{|l|}{ Bed boundary conditions: } \\
\hline No slip (1) or partial slip (2)? & 2 & 2 & 2 & 2 & 2 & 2 & 1 & 1 & 1 \\
\hline Validation $^{\mathrm{a}}$ & $U_{0}$ (this study) & - & $U_{0}$ (this study) & - & $q_{\mathrm{s}}$ & $q_{\mathrm{s}}$ and $c$ & $\tau_{b}$ and $U_{0}$ & - & $z_{\mathrm{b}}$ \\
\hline
\end{tabular}

${ }^{\mathrm{a}} U_{0}, q_{\mathrm{s}}, c, \tau_{\mathrm{b}}$ and $z_{\mathrm{b}}$ denote validation on wave averaged velocity, sediment transport rate, concentration profiles, bed shear stress and bed levels/ morphodynamic evolution respectively.

by mass transport or radiation stress gradients is included. Therefore, shear and all vertical gradients in turbulence properties will be confined to the wave boundary layer, resulting in upper boundary conditions:

$$
\left.v_{t} \frac{\partial u}{\partial z}\right|_{z=t o p}=0 \quad ;\left.\quad \frac{\partial k}{\partial z}\right|_{z=t o p}=0 \quad ;\left.\quad \frac{\partial \varepsilon}{\partial z}\right|_{z=t o p}=0
$$

being applicable for a domain size exceeding the boundary layer thickness. In the match model formulation, application of these conditions is very well justified for comparison with experiments in oscillating flow tunnels in combination with a domain size that is half the tunnel height, forming a frictionless rigid lid acting as a line of symmetry. One could argue that these conditions are less suitable for simulation of net boundary layer currents from flume experiments, because the conditions slightly incorrectly assume no transfer of momentum by shear stress at the upper boundary. This may introduce possible model sensitivity to the domain height $Z$. However, sensitivity tests show that the dependency of the mean current for $Z$ vanishes for $Z$ is larger than around two and a half times the boundary layer thickness (tests not shown here).

\subsection{Relation to Other Numerical Boundary Layer Models}

[14] The order of the advective terms in equations (1), (4) and (5) (2nd and 3rd term) compared to the others is $\mathrm{O}\left(\hat{u}_{\infty} / c\right)$. For waves in prototype situation, $\mathrm{O}\left(\hat{u}_{\infty} / c\right)$ is generally smaller than 0.3 . Although the unsteady horizontal flow in the wave boundary layer can be predicted rather well with only the terms of $O(1)$, it is essential to include these term to study the net current under waves, because the progressive wave streaming is driven by the (nonzero) wave averaged vertical advective transport of horizontal momentum into the wave boundary layer. With these terms turned off, free surface effects are neglected and our present model (called BL2-model) reduces again to the first order tunnel version (BL1-model) as used by Ruessink et al. [2009] and Hassan and Ribberink [2010]. The BL-2 model can be considered as a representative RANS-boundary layer model with $k-\varepsilon$ turbulence formulations that includes the nonlinear advective terms. It has strong similarities with the numerical models of Henderson et al. [2004] and Holmedal and Myrhaug, [2009], although there are small differences in the forcing and in the bed boundary condition (see Table 1 for an overview of model characteristics). Table 1 also shows the type of model validation carried out with these models so far, showing that the nonlinear second-order models (BL2-type) are still lacking a validation with detailed velocity data measured in the wave boundary layer under controlled conditions. Information on the numerical solution method as applied in BL-1 and BL-2 can be found in Appendix A.

\section{Validation}

\subsection{Test Cases}

[15] We validate the model with measurements of periodaveraged and time-dependent horizontal velocities from laboratory experiments on boundary layer flow. Because of our focus on the hydrodynamics, we use fixed bed experiments. Four cases with various flow conditions have been selected, to cover situations with the various types of streaming both in isolation and combination.

Table 2. Selected Validation Cases

\begin{tabular}{|c|c|c|c|c|c|c|c|c|c|}
\hline $\mathrm{Nr}$ & Author & Test Name & Type of Flow & $\begin{array}{l}\text { Type of } \\
\text { Facility }\end{array}$ & $\begin{array}{l}\text { Length } L \\
\quad(\mathrm{~m})\end{array}$ & $\begin{array}{l}\text { Width } W \\
\quad(\mathrm{~m})\end{array}$ & Roughness Method & $\begin{array}{l}\text { Size } \\
(\mathrm{mm})\end{array}$ & $\begin{array}{l}\text { Measurement } \\
\text { Method }\end{array}$ \\
\hline 1 & Klopman [1994] & WMN & Sinusoidal waves & Flume & 46.0 & 1.00 & Glued grains & $\varnothing=2.0$ & LDV \\
\hline 2 & Campbell et al. [2007] & CA505 & $\begin{array}{l}\text { Velocity-skewed } \\
\text { oscillatory flow }\end{array}$ & Tunnel & 10.0 & 0.300 & Glued grains & $\varnothing=0.46$ & PIV \\
\hline 3 & Van $\operatorname{der} A$ et al. [2011] & S757012c & $\begin{array}{l}\text { Acceleration-skewed } \\
\text { oscillatory flow }\end{array}$ & Tunnel & 10.0 & 0.300 & Glued grains & $\varnothing=0.46$ & PIV \\
\hline 4 & Van Doorn [1981] & $\begin{array}{c}\mathrm{V} 00 \\
(\mathrm{RA} \text { and } \mathrm{RB})\end{array}$ & Velocity-skewed waves & Flume & 30.0 & 0.500 & $\begin{array}{c}\text { Fixed bars, } \\
\text { spacing } 15 \mathrm{~mm}\end{array}$ & $\begin{array}{l}\square=2.0 \times 2.0 \\
\text { (cross-section) }\end{array}$ & LDV \\
\hline
\end{tabular}




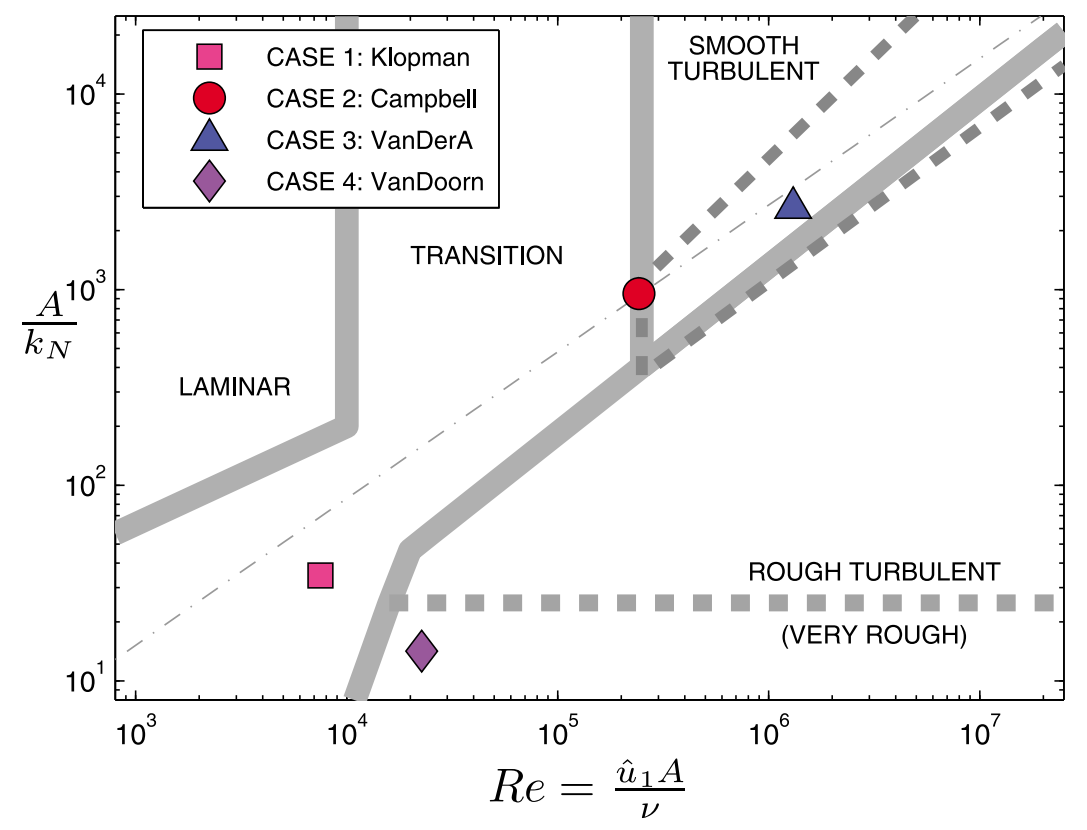

Figure 1. Delineation of flow regimes with position of validation cases, following the example of Davies [1980]. Thick gray lines based on Jonsson [1966, 1980]. Thick dashed dark gray line: transition zone from rough turbulent to smooth turbulent as derived from Fredsøe and Deigaard [1992, Figure 2.13]. Thick dashed light gray line: transition from rough to very rough turbulent flow, with $2 \mathrm{D}$ effects around roughness elements (e.g., ripples) from Davies and Villaret [1999]. Thin dash-dotted line: line of $\delta_{\mathrm{v}} / k_{\mathrm{N}}=1$, an indication for the rough-smooth transition.

[16] Table 2 lists the four selected test cases. CASE 1 comes from small scale flume experiments in the Delft Scheldt Flume by Klopman [1994], with free surface waves with relatively small amplitudes $(T=1.44 \mathrm{~s}, a=0.06 \mathrm{~m}, h=$ $0.50 \mathrm{~m}$ ) and therefore nearly linear, sinusoidal form. With velocity-skewness nearly absent, we expect the net current to be determined by progressive wave streaming and a return current only, the latter compensating for streaming induced mass transport and Stokes' drift in the closed facility. CASE 2 and 3 stem from experiments in the Aberdeen Oscillating Flow Tunnel by respectively Campbell et al. [2007] and [Van $\operatorname{der} A$ et al., 2011]. In tunnel experiments, the vertical component of the orbital velocity and therefore progressive wave streaming is absent. In CASE 2 , with velocity-skewed oscillatory flow, the mean current is determined by the offshore velocity-skewness streaming and a return current that follows from the restriction of zero net mass transport in the closed tunnel facility. Also in CASE 3 , we expect an offshore streaming, but now originating from the acceleration-skewness of the flow [see Fuhrman et al., 2009a]. Although in acceleration-skewed flows maximum on- and offshore horizontal velocity are equally large, differences in turbulence will still be present between on- and offshore half cycle, due to differences in development time of the boundary layer. CASE 4 originates from small scale flume experiments by Van Doorn [1981], with free surface waves with relatively large amplitudes in relatively small water depths $(T=2.0 \mathrm{~s}, a=0.052 \mathrm{~m}, h=0.30 \mathrm{~m})$. Under such circumstances, nonlinear waveshapes will develop with increased wave crests and decreased and stretched wave troughs. This is expected to result in a combination of velocity-skewness streaming and progressive wave streaming inside the boundary layer. So, where the period-averaged velocity in CASE 1 to 3 arises from only one streaming mechanism (in combination with a return current), the net current in CASE 4 is generated by a combination of streaming mechanisms.

[17] More information on the experimental facilities, the way the bed has been roughened and the method of velocity measurement in the various experiments can be found in Table 2. Note that in all experiments horizontal and vertical velocity components were measured in the vertical symmetry plane along the length axis of the facility. In CASE 4, measurements were taken in a vertical line above (V00RA) and in between (V00RB) the bed roughness elements.

\subsection{Note on Flow Regimes}

[18] Starting from the assumption that the energetic waves in case of sheet flow sediment transport in prototype situation generate turbulent flow, the model has been formulated for turbulent flow over a hydraulically rough, but flat bed. Before discussing the validation results, we investigate whether the flow in the validation cases might also be considered as a turbulent flow over a rough but flat bed. First, note that the tunnel experiments aim for a one-to-one reproduction of the prototype situation, while the length scales of the waves in the small scale flume experiments of CASE 1 and 4 relate with approximately 1:10 to prototype length scales. Although this scaling will not influence the wave dispersion, the boundary layer flow might be affected. Orbital flow velocity and excursion $\hat{u}_{1}$ and $A$ will be much smaller, causing a reduction of the (wave) Reynolds number 
Table 3. Overview of Validation Cases: Flow and Bed Characteristics and Model Settings

\begin{tabular}{|c|c|c|c|c|c|c|c|c|c|c|c|c|}
\hline $\mathrm{Nr}$ & $\begin{array}{l}\text { Period } \\
\mathrm{T} \\
(\mathrm{s})\end{array}$ & $\begin{array}{l}\text { Roughness } \\
\text { Height } k_{\mathrm{N}} \\
\text { (m) }\end{array}$ & $\begin{array}{l}\text { Match } \\
\text { Level } z_{m} \\
(\mathrm{~mm})\end{array}$ & $\begin{array}{c}\text { Mean } \\
\text { Current } U_{0} \\
(\mathrm{~m} / \mathrm{s})\end{array}$ & $\begin{array}{c}\text { Velocity } \\
\text { Amplitude } \hat{u}_{1} \\
(\mathrm{~m} / \mathrm{s})\end{array}$ & $\begin{array}{c}\text { Velocity } \\
\text { Amplitude } \hat{u}_{2} \\
(\mathrm{~m} / \mathrm{s})\end{array}$ & $\begin{array}{c}\text { Velocity } \\
\text { Skewness } \\
R(-)\end{array}$ & $\begin{array}{c}\text { Acceleration } \\
\text { Skewness } \\
\beta(-)\end{array}$ & $\begin{array}{c}\text { Orbital } \\
\text { Excursion } \\
A(\mathrm{~m})\end{array}$ & $\begin{array}{c}\text { Reynolds } \\
\text { Number } \\
\operatorname{Re}(-)\end{array}$ & $\begin{array}{c}\text { Relative } \\
\text { Roughness } \\
A / k_{\mathrm{N}}(-)\end{array}$ & $\begin{array}{c}\text { Used } \\
\text { Model } \\
\text { Version }\end{array}$ \\
\hline 1 & 1.44 & $1.2 \mathrm{E}-3$ & 10.0 & $9.44 \mathrm{E}-4$ & 0.181 & 0.006 & 0.51 & 0.50 & $4.15 \mathrm{E}-2$ & $7.5 \mathrm{E} 3$ & $3.5 \mathrm{E} 1$ & BL2-match \\
\hline 2 & 5.0 & 4.6E-4 & 30.8 & $-8.55 \mathrm{E}-3$ & 0.552 & 0.119 & 0.61 & 0.50 & $4.39 \mathrm{E}-1$ & $2.4 \mathrm{E} 5$ & $1.0 \mathrm{E} 3$ & BL1-match \\
\hline 3 & 7.0 & $4.6 \mathrm{E}-4$ & 61.0 & $1.94 \mathrm{E}-3$ & 1.088 & 0.265 & 0.51 & 0.75 & $1.21 \mathrm{E} 0$ & $1.3 \mathrm{E} 6$ & $2.6 \mathrm{E} 3$ & BL1-match \\
\hline 4 & 2.0 & $6.0 \mathrm{E}-3$ & 25.0 & $-2.79 \mathrm{E}-2$ & 0.267 & 0.071 & 0.63 & 0.51 & $8.50 \mathrm{E}-2$ & $2.3 \mathrm{E} 4$ & $1.4 \mathrm{E} 1$ & BL2-match \\
\hline
\end{tabular}

$\operatorname{Re}=\hat{u}_{1} A / v$ (with factor $10^{1.5}$ for mentioned scaling). For lower Reynolds numbers, turbulent flow can only be generated with larger (relative) bed roughness. Figure 1 shows the position of the experiments in a chart of the flow regimes as determined by the non-dimensional relative roughness $A / k_{\mathrm{N}}$ and the non-dimensional wave Reynolds number $R e$, with $k_{\mathrm{N}}$ the Nikuradse roughness height (values as discussed in section 3.3). The regime delineations are gathered from Jonsson [1966, 1980], Davies [1980], Fredsøe and Deigaard [1992, Figure 2.13] and Davies and Villaret [1999].

[19] Figure 1 shows that CASE 3 is at the border of the rough turbulent flow regime. The scaled flume experiment of CASE 4 is in the very rough turbulent regime. In this case, the relative large roughness elements might even cause $2 \mathrm{D}$ effects [Davies and Villaret, 1999], not accounted for in the flat bed model approach. Despite the large roughness, CASE 1 is situated just inside the transition from turbulent to laminar. Apparently the wave, with small amplitude to maintain linearity, was too small to generate fully turbulent boundary layer flow. Also CASE 2 is just outside the rough turbulent flow regime. Here, the roughness elements are of the same order of magnitude as the viscous sub-layer $\delta_{\mathrm{v}}$, and the flow tends to be of turbulence in hydraulically smooth conditions. The line of $\delta_{\mathrm{v}} / k_{\mathrm{N}}=1$, the dash-dotted line in Figure 1 , has been estimated from conventional expressions for friction velocity $u *$ in steady flow [Fredsøe and Deigaard, 1992; see also Justesen, 1988] (here $\alpha=11.7$ ):

$\delta_{v}=\alpha \frac{v}{u_{*}} ; \quad u_{*}=\sqrt{0.5 f_{w}} \hat{u}_{1, \infty} ;$

$f_{w}=\frac{2}{\sqrt{\mathrm{Re}}} ; \rightarrow \frac{\delta_{v}}{k_{N}}=\alpha \mathrm{Re}^{-3 / 4} \frac{A}{k_{N}}$

with $f_{\mathrm{w}}$ the friction factor.

[20] In this study, we use CASE 1 to 4 for validation of the rough turbulent boundary layer model. Some influence of changing $R e$ is included in the model (see equation (1)). Alternative formulations for the smooth turbulent or transitional regime and their influence on streaming are not explored in the present study.

\subsection{Simulation Set-Up}

[21] In order to force the model in a consistent way for the different test cases, we force the model to match the measured velocity signal at the measurement location closest to $2.5^{*} \delta_{\mathrm{s}}$, with $\delta_{\mathrm{s}}$ the boundary layer thickness estimate of [Sleath, 1987]:

$$
\frac{\delta_{s}}{k_{N}}=0.27\left(\frac{A}{k_{N}}\right)^{0.67}
$$

and $A$ the orbital excursion. Note that with the selection of a high matching level $z_{\mathrm{m}}$, a large degree of freedom is allowed for the net current inside the boundary layer, which yields a more conclusive model validation. However, selection of a high matching level also has disadvantages: the measurements could be affected by sidewall effects, non-hydrostatic pressure effects or other processes absent in the model. The present choice for $z_{\mathrm{m}}$ yields a consistent treatment of all validation cases and takes account of the mentioned considerations. The model domain size is set to five times the matching level. Another modeling choice concerns the bed roughness height. In CASE 1 we use a Nikuradse roughness height $k_{\mathrm{N}}=1.2 \mathrm{~mm}$ as derived by Klopman [1994] from experiments with current only. In the other validation cases we use $k_{\mathrm{N}}=\gamma d_{50}$, with $\gamma$ somewhere between 1 and 3 , the exact value chosen based on the best fit of computed and measured level of maximum amplitude of the first harmonic component of the time dependent signal $\left(\hat{u}_{1}\right)$. The used values for $z_{\mathrm{m}}$ and $k_{\mathrm{N}}$ can be found in Table 3 , together with information on the input velocity signal, characterized by velocity-skewness and acceleration-skewness parameters $R$ and $\beta$, with:

$$
R=\frac{u_{\infty \text { max }}}{u_{\infty \text { max }}+\left|u_{\infty \text { min }}\right|} ; \quad \beta=\frac{\dot{u}_{\infty, \max }}{\dot{u}_{\infty, \max }+\left|\dot{u}_{\infty, \min }\right|} .
$$

where $u_{\infty}$ and $\dot{u}_{\infty}$ are the velocity and acceleration of the free stream respectively.

\subsection{Validation Results}

[22] The results are presented in Figures 2 and 3. These figures show the mean $U_{0}$ and the amplitude $\hat{u}$ and phase $\theta$ of the harmonic components of the measured and computed horizontal velocity $u(z, t)$, where:

$$
u(z, t)=U_{0}(z)+\sum_{n=1}^{n_{\max }} \hat{u}_{n}(z) \cos \left\{n \omega t+\theta_{n}(z)\right\}
$$

First, we consider the time-dependent flow, focusing the model-data comparison on the features boundary layer thickness, phase lead and velocity overshoot. The phase lead, increasing with decreasing distance to the bed, and the velocity overshoot, an increased maximum orbital velocity just inside the wave boundary layer, (both compared to the free stream), are visible in Figures $2 b, 2 c, 3 b$, and $3 c$, that show respectively amplitude $\hat{u}_{1}$ and phase $\theta_{1}$ of the first harmonic component. As proxy of the thickness, we look to the level where $\hat{u}_{1}$ has its maximum. Note that this feature was actually used for a slight tuning of roughness $k_{\mathrm{N}}$. We observe from the Figures $2 b, 2 c, 3 b$, and $3 c$ that the velocity overshoot and phase lead are present in the model results for 

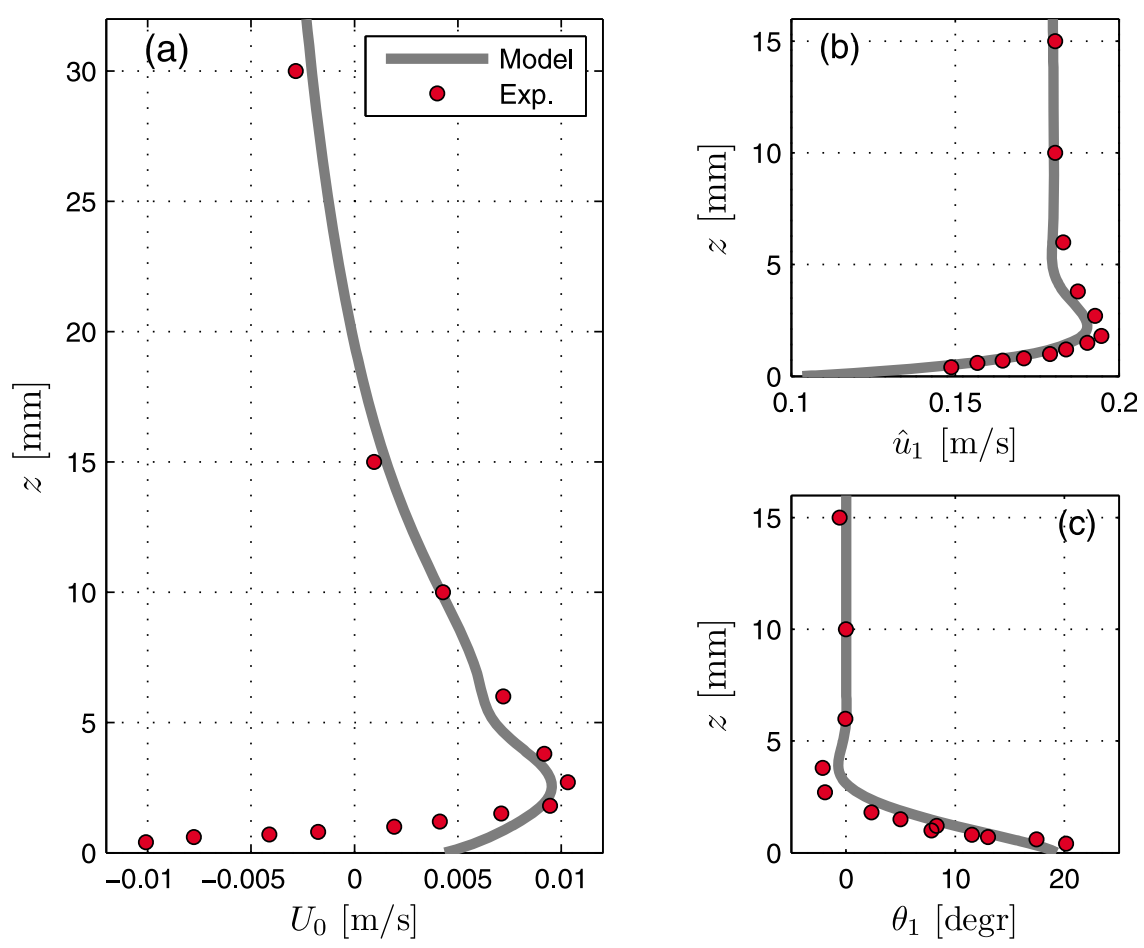

Figure 2. Model-data comparison on (a) wave averaged velocity $U_{0}$ and (b) amplitude $\hat{u}$ and (c) phase $\theta$ of 1 st harmonic component of the horizontal velocity for validation case 1: Klopman (see Tables 2 and 3 ). Positive velocities in (a) are directed onshore.

$\hat{u}_{1}$ and phase $\theta_{1}$ in all cases. For CASE 2 to 4 , the data also show a velocity overshoot in $\hat{u}_{2}$ and $\hat{u}_{3}$ (respectively plots $3 \mathrm{~d}$ and 3f) and a phase lead in $\theta_{2}$ and $\theta_{3}$ (respectively plots $3 \mathrm{e}$ and $3 \mathrm{~g}$ ). These features are also present in the model results. We especially point at the neat reproduction of the local minimum and two velocity overshoots in $\hat{u}_{3}$ of CASE 3 with acceleration-skewed flows. Note that for this case the third harmonic is more important than in the other cases (compare $\left.\hat{u}_{3} / \hat{u}_{1}\right)$. In aid of further model skill assessment, Table 4 provides quantitative measures of the reproduction quality: $S\left(\hat{u}_{\mathrm{n}, \max }\right)$ is the ratio of maximum amplitude for component $n$ in model and data, $S\left(\theta_{\mathrm{n}, \mathrm{z}=\mathrm{min}}\right)$ is the ratio of modeled and measured phase lead for component $n$ at the lowest data point. Figures 2 and 3 and Table 4 show that $0.8<\mathrm{S}<1.2$ for most of the cases. For CASE 2 and especially 4 the nearbed phase lead is predicted somewhat worse. We briefly return on explanations of this mismatch in section 3.5 and on implications hereof for further model application in section 5 .

[23] Next, we consider the period averaged horizontal current velocity $U_{0}$, comparing model and data for direction, magnitude and shape of the streaming profile. The quality of the reproduction is again quantified in Table 4 with $S\left(\left|U_{0}\right|\right.$, max $)$ the ratio of maximum absolute streaming velocity inside the boundary layer in model and data, and $S\left(z\left(\left|U_{0}\right|\right.\right.$,max $\left.)\right)$ the ratio of the level of maximum streaming in model and data. For CASE 1 to 3, direction and profile shape of $U_{0}$ are correctly reproduced by the model. Consistent with the expected dominance of progressive wave streaming beneath a linear wave, the results in CASE 1 show an onshore current inside the wave boundary layer, even though the mean pressure gradient generates an offshore current. The absence of a negative horizontal velocity component in the model results close to the bed is not considered as a major defect. It should be noted that in this scaled flume experiment the grains $(d \approx 2 \mathrm{~mm})$ were very large compared to the wave boundary layer thickness (approximately $6 \mathrm{~mm}$ ). Therefore, Klopman [1994, pp. 33] attributed these negative horizontal velocity components to the local effect of individual sand grains at the particular horizontal position where the measurements were taken. For CASE 2 and 3, both data and model show an offshore boundary layer current, consistent with the expected waveshape streaming for both velocityskewed and acceleration-skewed oscillatory flow. We observe in Figure 3 for CASE 2 a clear overestimation of $\left|U_{0, \max }\right|$ and, like in the time-dependent flow for this case, a mismatch in the 3 to 4 lowest measurement locations. On the other hand, $U_{0}$ is neatly reproduced in CASE 3 . This is an important result, because earlier effort to reproduce the (direction of the) mean flow in acceleration-skewed oscillations using an analytical boundary layer model [Gonzalez Rodriquez, 2009, Figures 4-14] (basically the model of Trowbridge and Madsen [1984b] with adapted upper boundary conditions to account for return currents in the closed facility) was not successful. An analysis of the contributions from the various harmonic components to the mean shear stress showed that the contribution of the 3rd harmonic components of eddy viscosity and horizontal velocity was significant. These components were not included in the analytical models. We therefore believe that the success of the present model to reproduce offshore 

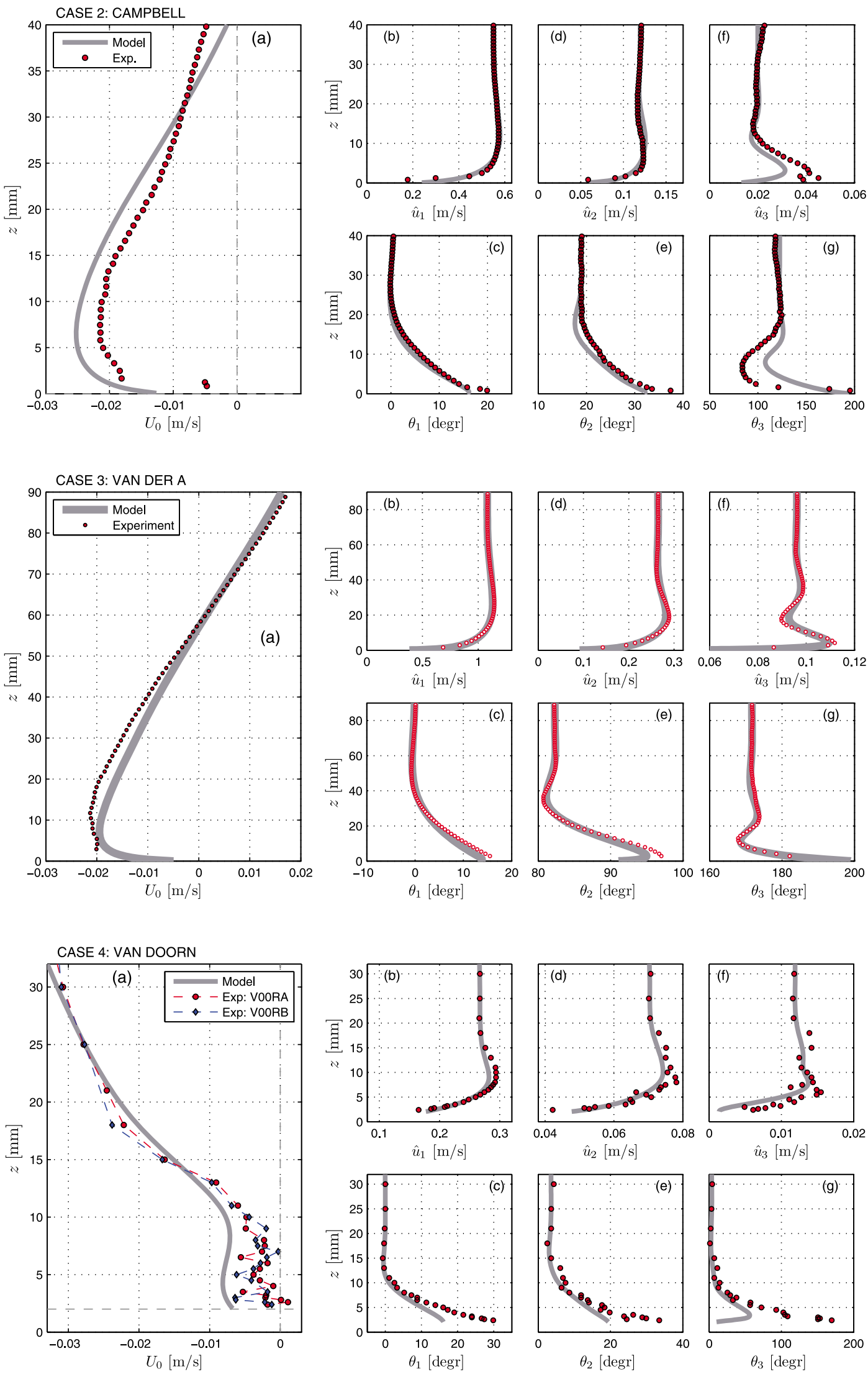

Figure 3. Model-data comparison on (a) wave averaged velocity $U_{0}$ and (b, d, f) amplitudes and (c, e, g) phases of the first three harmonic velocity components as function of $z$ for validation cases 2, 3 and 4 (see Tables 2 and 3). Positive values in Figure 3a: onshore directed velocities. 
Table 4. Quantification of the Reproduction Quality by Model/Data Ratios

\begin{tabular}{|c|c|c|c|c|c|c|c|c|}
\hline \multirow[b]{2}{*}{ Case } & \multicolumn{3}{|c|}{ Amplitude } & \multicolumn{3}{|c|}{ Phase Lead } & \multicolumn{2}{|c|}{ Mean } \\
\hline & $S\left(\hat{u}_{1, \max }\right)$ & $S\left(\hat{u}_{2, \max }\right)$ & $S\left(\hat{u}_{3, \max }\right)$ & $S\left(\theta_{1, \mathrm{z}=\min }\right)$ & $S\left(\theta_{2, \mathrm{z}=\min }\right)$ & $S\left(\theta_{3, \mathrm{z}=\min }\right)$ & $S\left(\left|U_{0}\right|_{, \max }\right)$ & $S\left(z\left(\left|U_{0}\right|, \max \right)\right)$ \\
\hline 1 & 0.98 & not rel. ${ }^{\mathrm{a}}$ & not rel. ${ }^{\mathrm{a}}$ & 0.94 & not rel. ${ }^{\mathrm{a}}$ & not rel. ${ }^{\mathrm{a}}$ & 0.93 & 0.94 \\
\hline 2 & 1.01 & 1.02 & 0.72 & 0.80 & 0.70 & 0.86 & 1.16 & 0.93 \\
\hline 3 & 0.99 & 0.97 & 0.97 & 0.88 & 0.88 & 1.00 & 0.92 & 0.67 \\
\hline 4 & 0.96 & 0.95 & 0.89 & 0.53 & 0.58 & 0.06 & $+/-2$ & - \\
\hline
\end{tabular}

${ }^{\mathrm{a}}$ Not relevant.

streaming in acceleration-skewed flow is essentially because the model includes the higher harmonic components.

[24] For CASE 4 the (negative) streaming is clearly overpredicted by the model, however it should be realized that the measured mean velocities near the bed are very close to zero and show a relatively large scatter. The absolute magnitude of the overprediction is only a few $\mathrm{mm} / \mathrm{s}$. Figure 4 shows that the present model clearly gives improved predictions compared to the analytical model of Trowbridge and Madsen [1984b] (TM84). The reason why we compare with this model is that it is essentially this model that has been used by Gonzalez Rodriquez and Madsen [2011] (GRM) to investigate the influence of streaming on sediment transport (medium-sized sand). Note that the adapted boundary conditions of GRM compared to TM84, incorporating the negative return flow, will lead to an even worse analytical prediction for $U_{0}$ in CASE 4. Like TM84, the present model (BL2-match) shows a clear competition between the generation of offshore directed streaming close to the bed and onshore directed streaming at a higher levels inside the boundary layer (local minimum and maximum). Above $z=9 \mathrm{~mm}$, the $U_{0}$-profile bends in offshore direction: Within the boundary layer, both velocity-skewness streaming and progressive wave streaming are present, but keep each other (in this case) practically in balance, explaining measured net currents so close to zero. Outside the boundary layer, however, where these mechanisms are not active anymore, the return current is the dominating mechanism governing $U_{0}$. To illustrate this balance quantitatively, we add simulations to Figure 4 with the velocity-skewness respectively the progressive wave streaming mechanism turned off. The first is achieved by forcing the BL2-match model with mean and first harmonic only (a sinusoidal wave), the second by forcing the BL1-match model with the complete measured $u(z, t)$ at $z_{\mathrm{m}}$. The first predicts onshore streaming, while the latter predicts far too much offshore streaming. Both are clearly further off than the complete BL2-match model. The improved predictions of the present model compared to TM84 can probably be explained by the turbulence memory effect, as included in the $\mathrm{k}-\varepsilon$ model: Turbulent kinetic energy generated by the strong onshore movement is diffused upward. Because this takes time, this t.k.e. can even end up in offshore directed flow, thus reducing the difference in turbulent shear stresses during onand offshore flow and therefore also reducing the offshore velocity-skewness streaming component.

\subsection{General Model Behavior}

[25] To explain the underestimation of the phase lead in CASE 4, the behavior of the model under influence of changing roughness has been investigated in more detail by studying the computed friction factor $f_{\mathrm{w}}$ and level of maximum velocity overshoot $z\left(\hat{u}_{1, \max }\right)$ for sinusoidal oscillations (so no streaming involved). It appears that inside the rough turbulent regime, model results for $f_{\mathrm{w}}$ and $z\left(\hat{u}_{1, \max }\right)$ are well described with:

$$
f_{w}=0.062\left(\frac{A}{k_{N}}\right)^{-0.3}, \quad \frac{z_{u_{1}, \max }}{k_{N}}=0.135\left(\frac{A}{k_{N}}\right)^{0.75}
$$

When we compare the model predicted $f_{\mathrm{w}}$ with (empirical) relations from literature (Figure 5), we observe that for $A / k_{\mathrm{N}}>50$ the relations from literature are reproduced rather well. However, for $A / k_{\mathrm{N}}<50$ the friction is underpredicted. Such model performance for oscillatory flows has been observed before (see e.g., Justesen [1988] ( $k-\varepsilon$ turbulence closure) and Fuhrman et al. [2009a] (k- $\omega$ turbulence closure)) and is ascribed to the fact that the model does not consider the 2-dimensional flow phenomena taking place around the relatively large roughness elements in the very rough turbulent regime. An under predicted friction factor

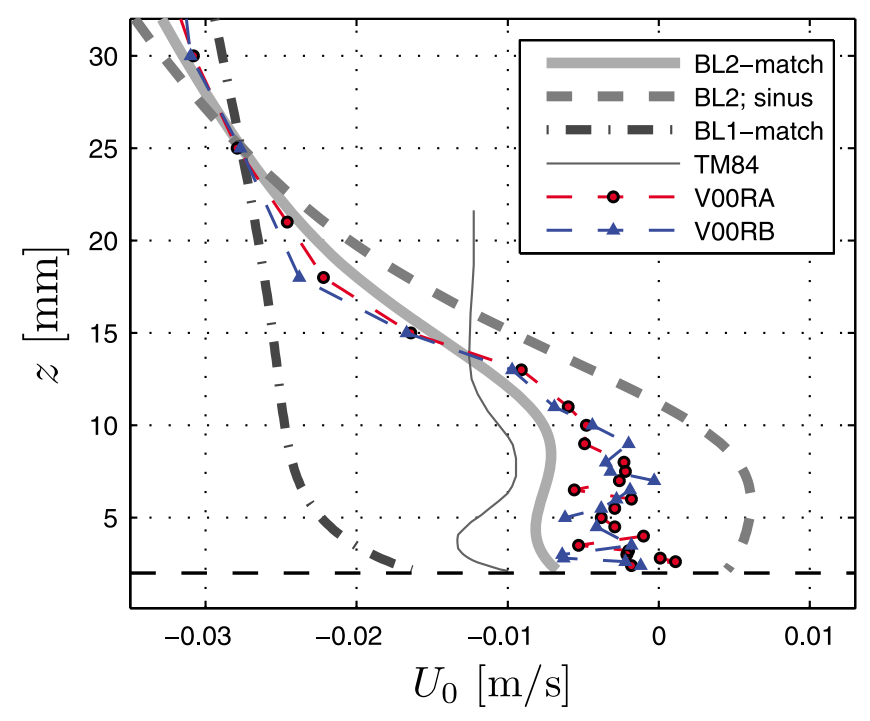

Figure 4. Period averaged velocity $U_{0}$ computed with: 1) complete model (BL2-match model, solid curve); 2) velocity-skewness streaming excluded (BL2-sinus, dashed line); 3) progressive wave streaming excluded (BL1-match model, dash-dotted line), compared with measurements of Van Doorn [1981] in the vertical above (V00RA) and in between (V00RB) the roughness elements, and the analytical results of Trowbridge and Madsen [1984b] (TM84, thin solid line). Positive velocities are onshore directed. All model simulations are forced at $z=25 \mathrm{~mm}$. 


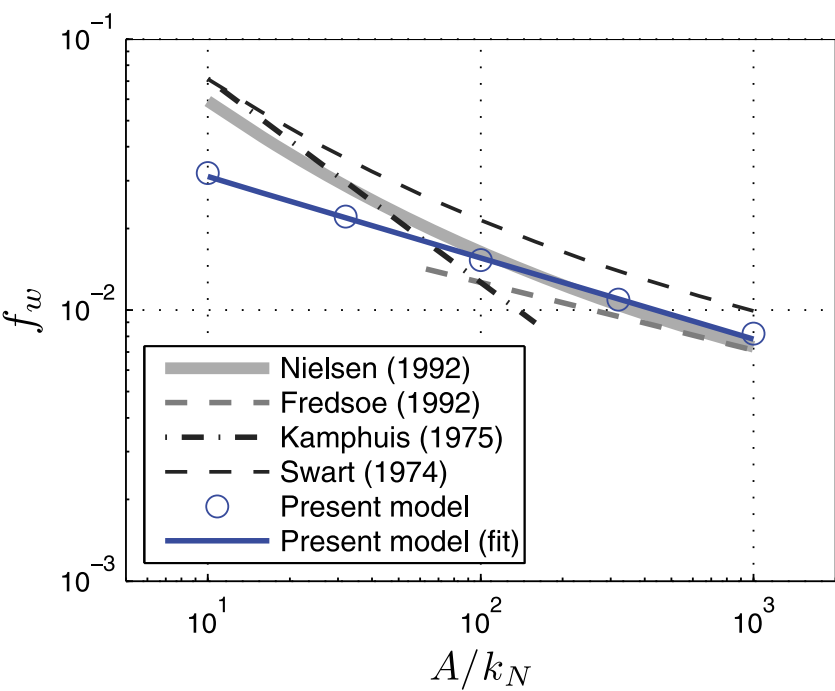

Figure 5. Wave friction factor $f_{\mathrm{w}}$ versus $A / k_{\mathrm{N}}$ from the present model compared to various (empirical) relations from literature.

in CASE 4 would indeed explain the underestimation of the phase lead.

\section{Analysis of Streaming Generating Mechanisms}

[26] We subsequently investigate how the observed direction and shape of the net current profiles can be attributed to the various streaming mechanisms and their potential competition. Next, we explore systematically how this competition will change for changing wave and bed conditions. Finally, we study the effects of the mean pressure gradient.

\subsection{Streaming Mechanisms in the Validation Cases}

[27] We use our model to assess and distinguish the influence of the various mechanisms on the $U_{0}$ profile. First, a 'shape'-expression has been derived from the momentum balance (by period averaging and integration over $z$, see also Appendix B, overbar indicates period-averaging):

$$
\rho\left(v+\bar{v}_{t}\right) \frac{\partial \bar{u}}{\partial z}=\rho\left(\overline{u w}-\overline{u w}_{\infty}\right)+\frac{\partial \bar{p}}{\partial x}(z-h)-\rho \widetilde{v}_{t} \frac{\partial \widetilde{u}}{\partial z}
$$

This shows the influence of the various momentum transferring mechanisms to the mean velocity gradient (note that the wave averaged viscosity is always positive) or more precise the current-related part of the mean shear stress. The terms on the right hand side show respectively the contributions from 1) mean momentum transport by vertical velocity ('wave Reynolds stress') driving the progressive wave streaming, 2) the wave-averaged pressure gradient, and 3) differences in turbulence between the on- and offshore phase of the wave driving the waveshape streaming (wave-related mean shear stress). Second, profiles of all these terms have been computed from the model results. A direct comparison of the four validation cases is possible after normalization. The vertical distance has been scaled by $\delta^{*}$, an estimate for the thickness of the turbulent wave boundary layer [Nielsen, 1992; Swart, 1974]:

$$
\delta^{*}=\sqrt{\frac{f_{w}}{2}} A ; \quad f_{w}=\exp \left\{5.5\left(\frac{A}{k_{N}}\right)^{-0.2}-6.3\right\}
$$

The stress contributions are scaled by the maximum bed shear stress $\tau_{\mathrm{b}, \mathrm{m}}$ exerted by a sinusoidal oscillatory flow with a velocity amplitude $\hat{u}_{1 \infty}$ identical to the validation case [see Fuhrman et al., 2009a]. Here, this $\tau_{\mathrm{b}, \mathrm{m}}$ was obtained from simulations, but can equally well be computed with $\tau_{\mathrm{b}, \mathrm{m}}=1 / 2 \rho f_{\mathrm{w}} \hat{u}_{1}^{2}$ and $f_{\mathrm{w}}$ according to (18). These results are shown in Figure 6.

[28] In Figures 6a-6d we observe the following (in order of increasing interest). No contribution of the wave Reynolds stress (Figure 6b) is present in the tunnel cases (CASE 2 and 3). A positive mean pressure gradient (Figure $6 \mathrm{c}$ ) is present in the flume cases (CASE 1 and 4), a negative in the tunnel cases, (a)

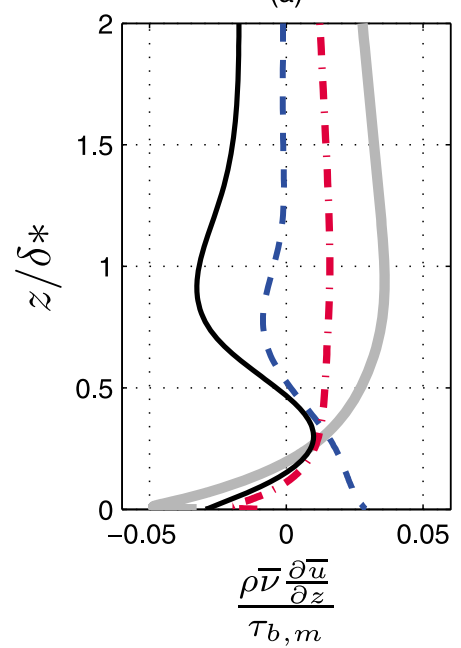

(b)

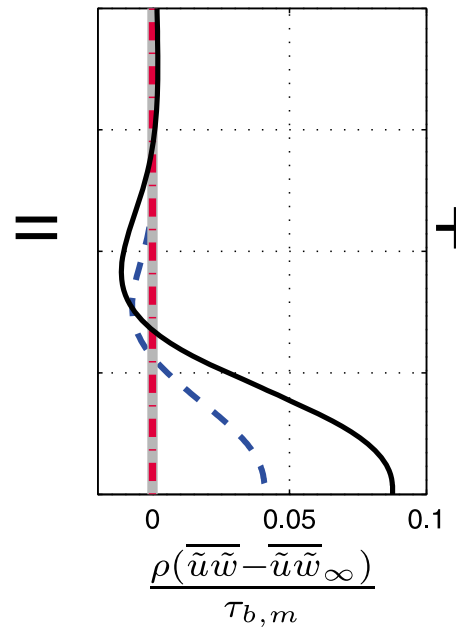

(c)

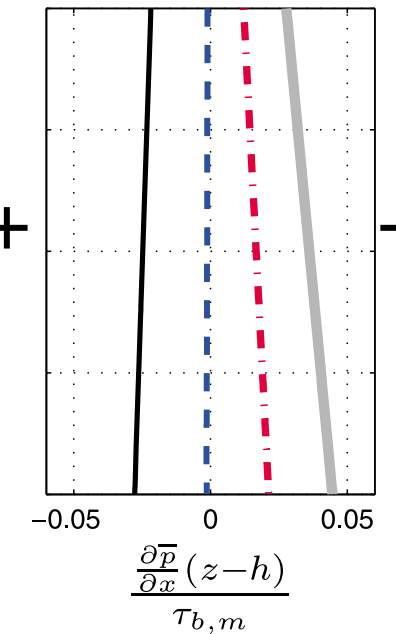

(d)

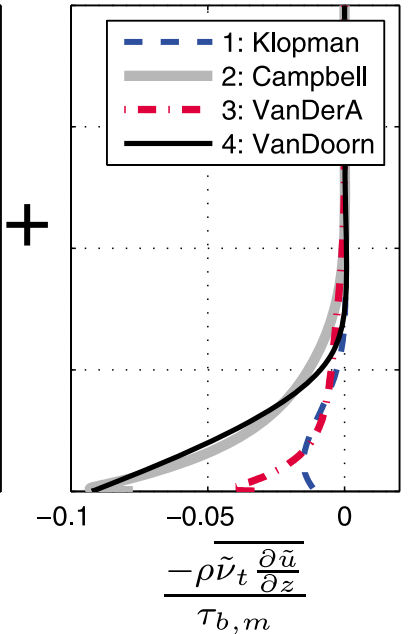

Figure 6. Normalized contributions to the current related mean shear stress (a) from the wave Reynolds stress (b), the mean pressure gradient (c) and the waveshape (d) for validation cases 1-4. 
consistent with the directions of the mass transport compensation currents. The waveshape related contribution (Figure 6d) is negative for all cases, running from a maximum negative value at or very near the bed toward zero around $\delta^{*}$. This contribution is not only present for the velocity-skewed oscillations/waves (CASE 2 and 4), but also under the acceleration-skewed oscillation (CASE 3), albeit smaller. Also the practically linear wave in CASE 1 shows a negative waveshape contribution (d). We ascribe this to the increased onshore and reduced offshore near bed velocities due to the positive progressive wave streaming, introducing a turbulence behavior like under velocity-skewed oscillation. The deviation of the wave Reynolds stress (b) from its free stream value has the same form in the two flume experiments: constant and positive close to the bed and subsequently twisting around zero with decreasing amplitude for increasing distance from the bed. For CASE 4, the summation in panel (a) shows a clear competition between the contribution from the wave Reynolds stress and from the wave-related mean stress. At low levels, apparently the waveshape streaming wins and the velocity gradient is negative. At higher levels, the gradient becomes positive and subsequently negative again, under influence of the progressive wave streaming mechanism. This explains the velocity profile in Figure 4, where the negative velocity is the result of velocity-skewness streaming, but the bulb in positive direction follows from the progressive wave streaming. Note that the latter has its level of maximum influence on a higher level than the first.

\subsection{Influence of Changing Wave and Bed Conditions}

[29] Under free surface waves in prototype situation, both streaming phenomena act simultaneously. However, their contribution can vary largely with varying wave conditions. When waves approach the shore, orbital velocities close to the bed will increase while the wave propagation velocity decreases. Therefore, progressive wave streaming may be expected to increase with decreasing depth. However, the waveshape will change simultaneously. Where waveshape streaming due to velocity-skewness is absent for linear waves offshore, it will also increase with decreasing depth. So it is not a priory clear which of the streaming mechanisms wins. Earlier analytical investigation of this balance by Trowbridge and Madsen [1984b] revealed a reversal of the streaming velocity at the edge of the bottom boundary layer from on- to offshore for relatively long waves. Holmedal and Myrhaug's [2009] numerical simulations showed increasing importance of velocity-skewness streaming over progressive wave streaming for increasing wave periods, qualitatively consistent with Trowbridge and Madsen [1984b]. Here, we use the validated numerical model for a systematic quantitative investigation on the balance between the competing mechanisms for changing wave and bed conditions on the shoreface. These general insights in streaming are considered to be valuable for the development of adequate hydrodynamic input for practical sand transport formulae.

\subsubsection{The Non-dimensional Parameter Domain}

[30] The hydrodynamics of the boundary layer above a flat horizontal bed under a free surface wave is completely described by the parameters $a, h, T, k_{\mathrm{N}}, g$ and $v$. With six dimensional parameters and two fundamental dimensions, this situation can be described by combinations of four basically independent non-dimensional parameters, e.g., $a / h$, $k h, A / k_{\mathrm{N}}$ and $R e$, respectively the relative wave amplitude, relative water depth, relative bed roughness and the (wave) Reynolds number. Note that other informative nondimensional parameters can be derived from these 4 parameters, for instance the parameter $\hat{u}_{1} / c$ that indicates the relative importance of the advective terms in the momentum equation (1), and the parameter $R$ that describes the degree of velocity-skewness (16). In contrast with tunnel experiments, velocity-skewness $R$ is not a free parameter under real free surface waves. It depends on the relative water depth $k h$ and relative wave amplitude $a / h$. To describe the shape of the near bed velocity signal as function of these parameters, a wave theory or model is needed. Using 2nd order Stokes theory, see equation (8), $R$ can be expressed as:

$$
R=\frac{1}{2}+\frac{3}{8} \frac{a k}{\sinh ^{3}(k h)} ;
$$

From the four non-dimensional parameters $a / h, k h, A / k_{N}$ and $R e$, the first three are considered most relevant studying streaming and shear stress in a turbulent wave boundary layer potentially inducing sheet-flow: wave condition parameters $a / h$ and $k h$ give the forcing of the boundary layer model, parameter $A / k_{\mathrm{N}}$ directly influences the friction of the flow over the bed. Within the (rough) turbulent flow regime, the influence of $R e$ on the boundary layer flow characteristics should diminish. Extensive tests on model behavior do confirm this and show that the area of $R e$-independent model results coincides quite well with the experimentally determined delineation of the rough turbulent flow regime (see Figure 1). Restricting our exploration to this flow regime, we therefore couple the Re number to the relative roughness $A / k_{\mathrm{N}}$ with:

$$
\operatorname{Re}=1.75 * 223\left(\frac{A}{k_{N}}\right)^{1.17}
$$

which is a line parallel to the turbulent delineation of Jonsson [1966] in Figure 1, inside the rough turbulent regime.

[31] We investigate the balance between velocityskewness streaming and progressive wave streaming in the turbulent wave boundary layer for a domain spanned by the remaining parameters $a / h, k h$ and $A / k_{\mathrm{N}}$. Because we use second order Stokes theory to determine the oscillating free stream velocity (model input), cases outside the domain of applicability of this theory (wave breaking, too much nonlinearity) have been excluded from the further procedure. The used restrictions are: $a / h<0.4$ and $R<0.625$ (coincides more or less with Ursell number $U=H L^{2} / h^{3}<45$, with $H$ and $L$ wave height and length respectively). See the delineation in Figure 7 (top). Within these limits, cases have been defined (circles, same figure), and simulations have been carried out using the BL2-free-model for zero mean pressure gradient. Following Trowbridge and Madsen [1984b], the computed streaming velocity just outside the boundary layer is taken as a measure in the visualization of the results. Dependency on $a / h$ is nearly completely 

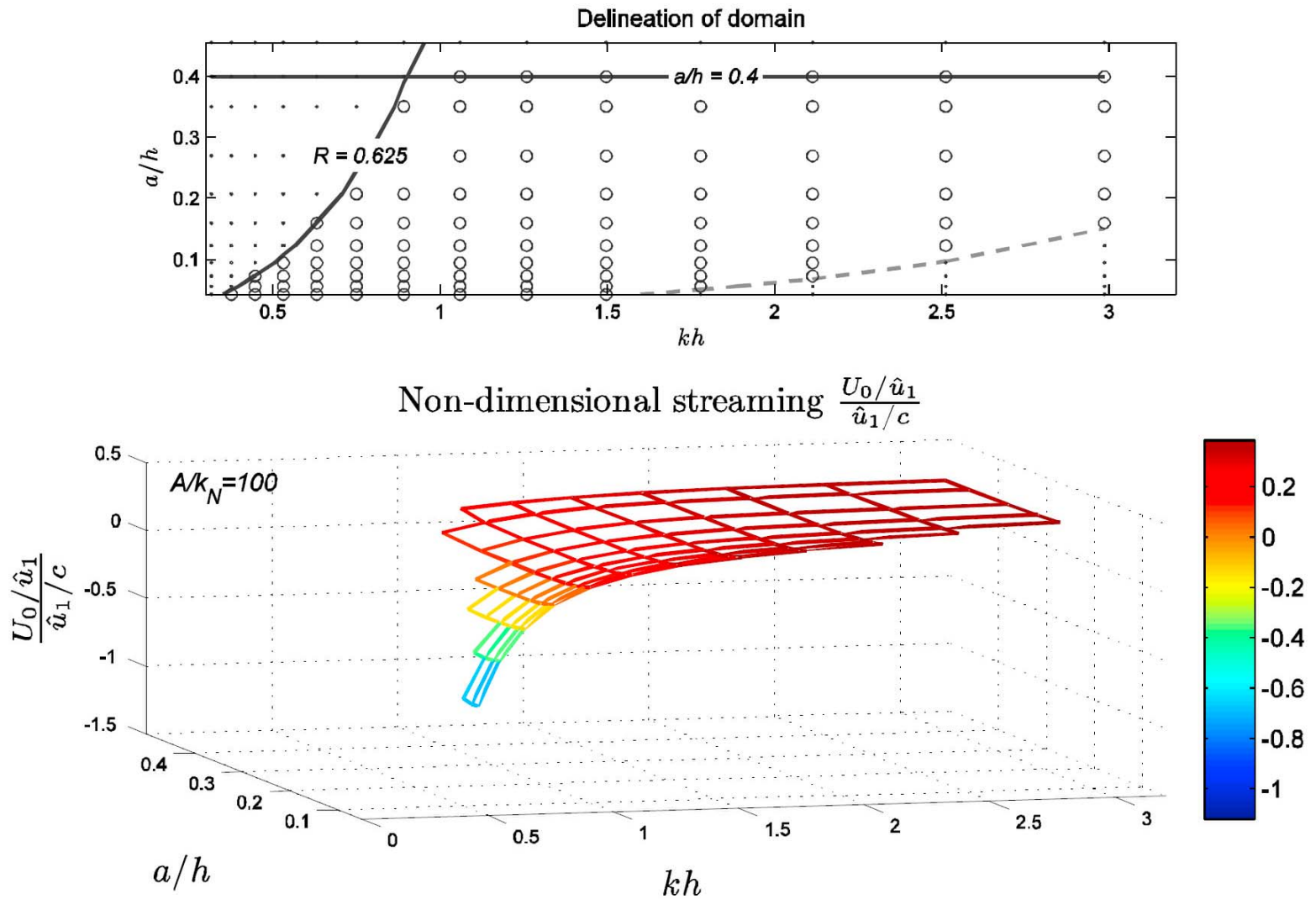

Figure 7. (top) Delineation of realistic parameter combinations in the plane spanned by $k h$ and $a / h$; (bottom) Non-dimensional streaming velocities at outer edge of the boundary layer as function of $k h$ and $a / h$ for $A / k_{\mathrm{N}}=100$.

removed from the visualization when the streaming is normalized as $\left(U_{0} / \hat{u}_{1}\right) /\left(\hat{u}_{1} / c\right)$. This can be seen from Figure 7 (bottom), showing results for $A / k_{\mathrm{N}}=100$. Only at the outer edges of the domain, the surface formed by the numerical results is slightly bent in $a / h$ direction (which is attributed to slight numerical inaccuracies in the extreme cases). Note that the $a / h$ independency in the mentioned normalization reduces the normalized streaming to a function of $k h$ and $A / k_{\mathrm{N}}$ only.

\subsubsection{Influence of Relative Water Depth $\boldsymbol{k h}$}

[32] Figure 8 shows the non-dimensional streaming as function of $k h$ for a single roughness. The results show a clear dependence on $k h$ : streaming is positive at large $k h$, but decreases more and more for decreasing $k h$. Simulations with waveshape effect and progressive wave effect only, clarify these results: at relatively deep water (large $k h$ ) the non-dimensional streaming is completely determined by the free surface effect. For decreasing relative water depth $(\mathrm{kh})$, the normalized progressive wave streaming stays nearly constant (also for strongly nonlinear waves, the contribution of higher harmonics to progressive wave streaming is small). However, the importance of waveshape effect relative to the free surface effect increases, resulting in a reversal from onto offshore. This $k h$ behavior is qualitatively consistent with the findings of Trowbridge and Madsen [1984b]. For $A / k_{\mathrm{N}}=$
320 , the numerical model gives the directional reversal close to $k h=0.8$.

[33] Before, we described that the two physical processes both become stronger when approaching the shore. We learn from Figure 8 that velocity-skewness streaming increases the most with decreasing water depth. Apparently, its driving force increases more than the mechanism driving the progressive wave streaming. As discussed in section 2 and confirmed by Figure 8 , contribution of the latter to $U_{0} / \hat{u}_{1}$ depends on the vertical advection of horizontal momentum that scales with $\hat{u}_{1} / \mathrm{c}$. The increasing relative contribution of waveshape streaming for decreasing water depth can then be explained from the scaling of $\hat{u}_{2} / \hat{u}_{1}$, which is proportional to $\hat{u}_{1} \mathrm{c}^{-1} / \sinh ^{2}(k h)$ when using Stokes' theory. This is confirmed by the simulations for waveshape streaming only that show results proportional to $1 / \sinh ^{2}(k h)$. Figure 8 also shows that the streaming from the full model is as good as equal to the sum of separate simulations with waveshape and progressive wave streaming only. This indicates that interaction between the two streaming mechanisms is generally small.

\subsubsection{Influence of Relative Bed Roughness $A / \boldsymbol{k}_{N}$}

[34] Figure 9 shows model results for the non-dimensional streaming velocity for various values of $A / k_{\mathrm{N}}$, together with the analytical results of Trowbridge and Madsen [1984b] (TM84). In the numerical results, the main influence of the 

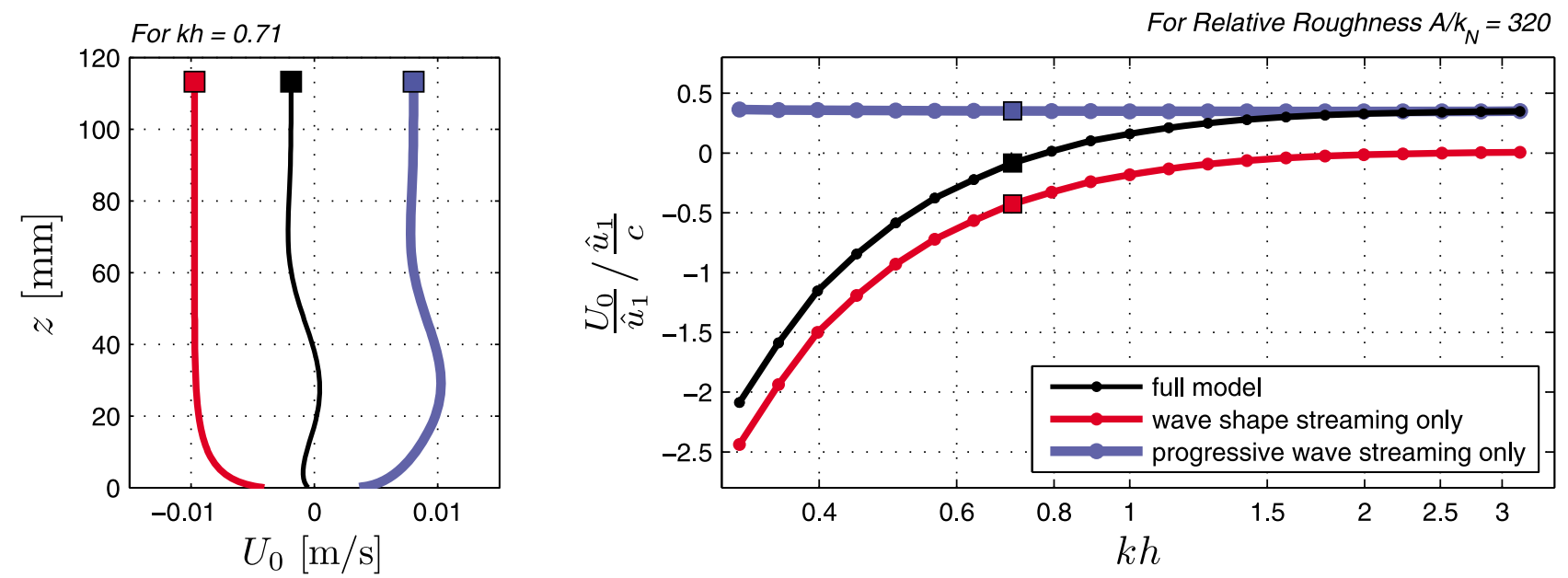

Figure 8. Streaming velocities from full model simulations (black), simulations with waveshape effect only (red), and free surface effect only (blue). (left) Streaming profiles for a single $k h$-value. (right) Non-dimensional streaming at the outer edge of the boundary layer as function of relative water depth $k h$ (on log-scale) for $A / k_{\mathrm{N}}=320$.

roughness is that for all $k h$ the streaming value shifts in negative direction for increasing $A / k_{\mathrm{N}}$, with decreasing shifts for larger values of $A / k_{\mathrm{N}}$. The results differ from TM84 in various ways. First, the simulated streaming velocities at $k h=3$, approximating the streaming from progressive wave streaming only, are smaller and much less sensitive for $A / k_{\mathrm{N}}$. Second, the numerically predicted $k h$ value of streaming reversal is higher. Finally, at low values of $k h$ the $A / k_{\mathrm{N}}$ influence is opposite in the two models. According to the analytical model results both streaming processes become stronger with increasing bed roughness (decreasing $A / k_{\mathrm{N}}$ ). We conversely found almost no influence of the roughness on the offshore waveshape streaming. Like in validation case 4, this can be explained by the diffusive transport of t.k.e., which is included in the present model with turbulence memory and $k-\varepsilon$ closure, and not in TM84, with an eddy viscosity being a function of the instantaneous shear velocity.

\subsubsection{Parameterizations}

[35] Parameterizations of the numerical results may be helpful to include progressive wave streaming and waveshape streaming into practical sand transport formulae, that either use a free stream velocity moment (Bagnold-Bailard type) or bed shear stress (Meyer-Peter and Müller type) as hydrodynamic input [e.g., van Rijn, 2007; Nielsen, 2006]. The results for the streaming at the top of a rough turbulent boundary layer can be parameterized as follows:

$$
\frac{U_{0} / \hat{u}_{1}}{\hat{u}_{1} / c}=0.345+0.7\left(\frac{A}{k_{N}}\right)^{-0.9}-\frac{0.25}{\sinh ^{2}(k h)}
$$

(with the first two terms parameterizing progressive wave streaming and the last term connected to waveshape streaming beneath Stokes waves).

[36] The current related mean bed shear stress and the contributions to it from the wave Reynolds stress and the waveshape effect (see equation (19)), have been studied just like the streaming velocities. When we normalize the contributions at the bed by $\tau_{\mathrm{b}, \mathrm{m}} \hat{u}_{1} / c$, the results shows a $k h$-dependency similar to Figure 8, but now independent of
$A / k_{\mathrm{N}}$. Without a mean pressure gradient, the total mean bed shear stress is equal to the wave Reynolds stress $\bar{\tau}_{b, W R S}=$ $-\rho \overline{u w}_{\infty}$. We found from the numerical simulations:

$$
\bar{\tau}_{b}=\rho\left[\left(v+\bar{v}_{t}\right) \frac{\partial \bar{u}}{\partial z}+\overline{\widetilde{v}_{t} \frac{\partial \widetilde{u}}{\partial z}}\right]=\bar{\tau}_{b, W R S}=0.430 \tau_{b, m} \hat{u}_{1} c^{-1}
$$

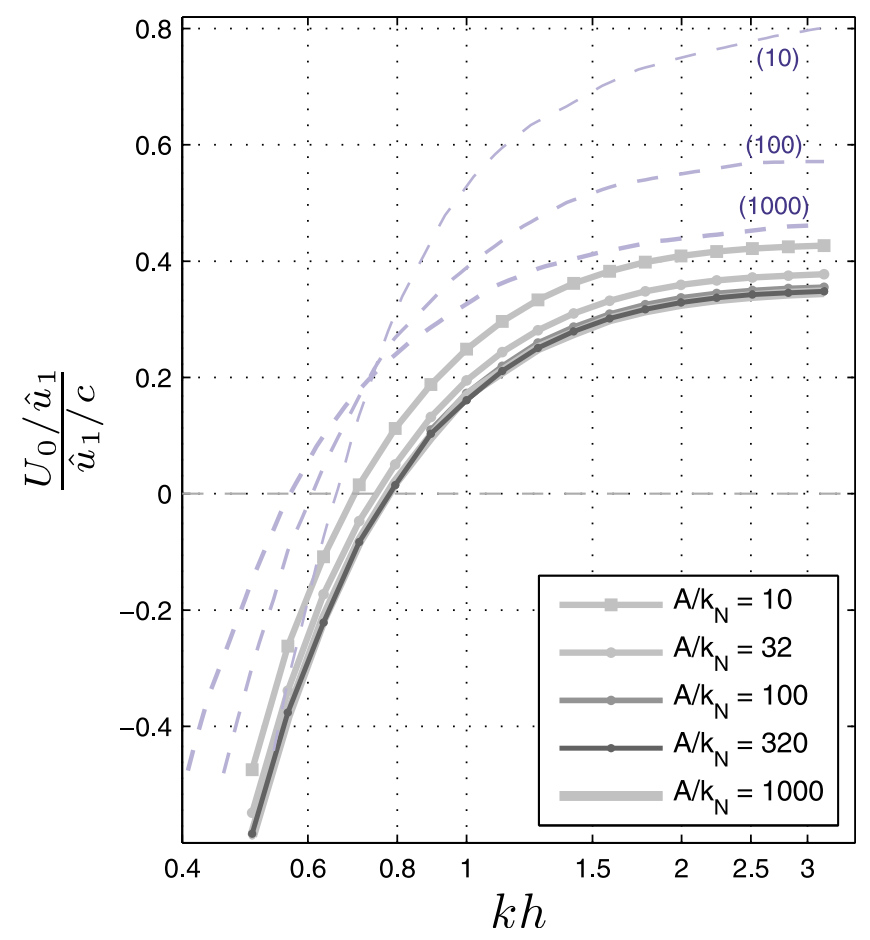

Figure 9. Non-dimensional streaming velocity at the outer edge of the boundary layer as function of $k h$ (log-scale) for various values of the relative roughness parameter $A / k_{\mathrm{N}}$. Solid lines: present model results. Dashed lines: analytical results of Trowbridge and Madsen [1984b]. 
(a)

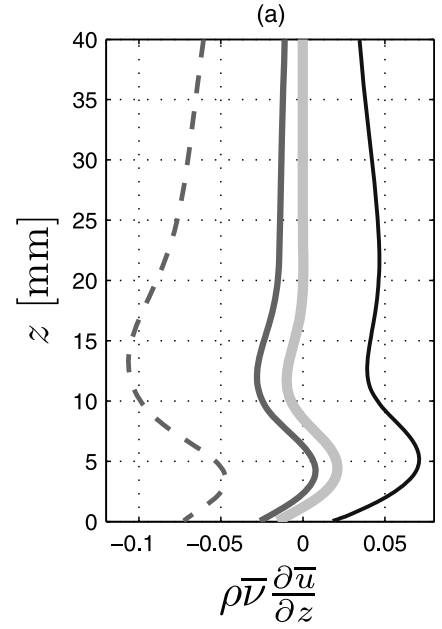

(b)

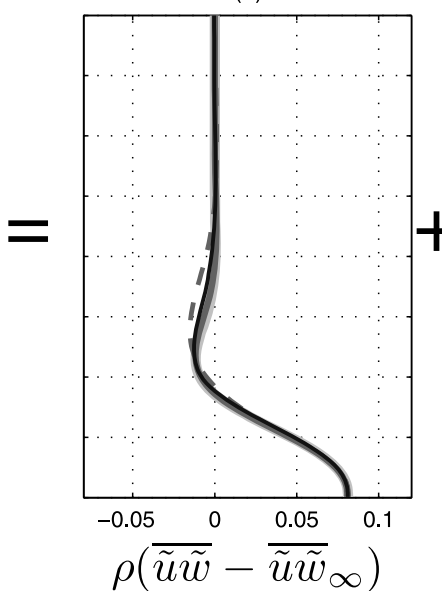

(c)

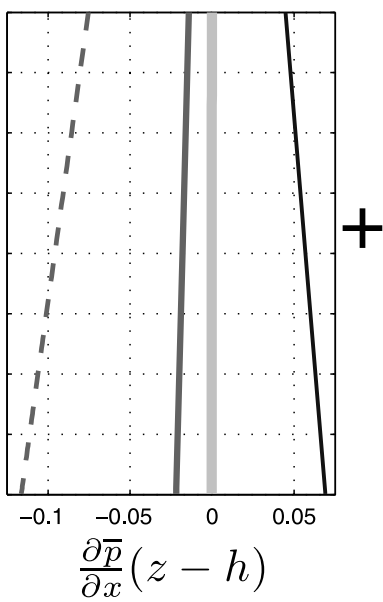

(d)

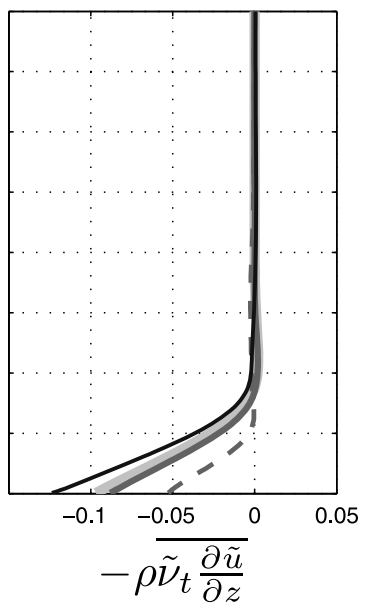

(e)

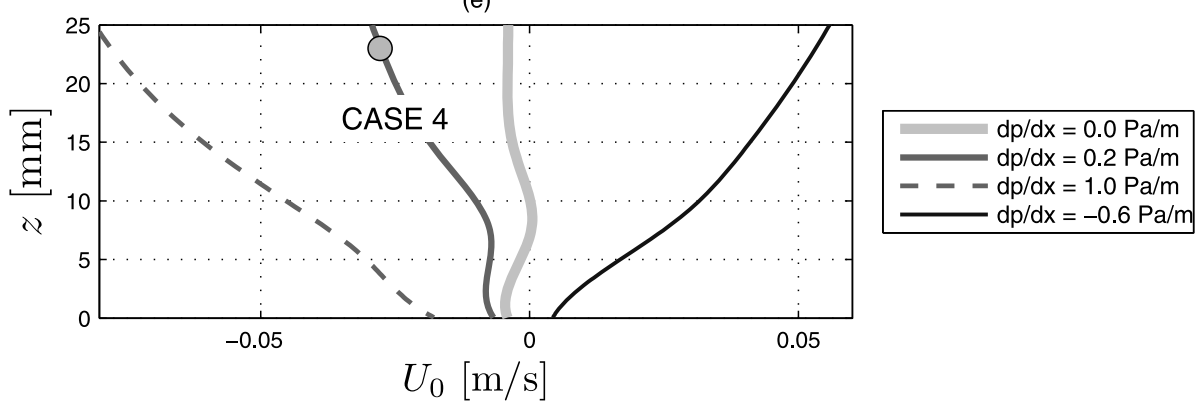

Figure 10. Contributions to the mean current related shear stress (a) from the wave Reynolds stress (b), the mean pressure gradient (c) and the waveshape (d) for case 4: Van Doorn, and three derived cases, namely with an increased positive (dashed line), a large negative (black solid line) and a zero (light gray line) mean pressure gradient. (e) Corresponding mean current profiles. Gray dot (Figure 10e): original matching level $z_{\mathrm{m}}$ and velocity $U_{0}\left(z=z_{\mathrm{m}}\right)$ for simulation of case 4. Model settings: domain height $h=$ $115 \mathrm{~mm}$ in all simulations.

With $\tau_{b, m}=1 / 2 \rho f_{w} \hat{u}_{1}^{2}$, this gives:

$$
\bar{\tau}_{b, W R S}=0.215 \rho f_{w} \hat{u}_{1}^{3} c^{-1}
$$

which numerically confirms earlier analytical estimates for $-\rho \overline{u w}_{\infty}$ from energy dissipation $D_{\mathrm{E}}$ in a sinusoidal oscillation:

$$
-\rho \overline{u w}_{\infty}=D_{E} / c \quad D_{E}=\overline{\vec{\tau}_{b}(t) \widetilde{u}_{\infty}(t)}=\frac{2}{3 \pi} \rho f_{w} \hat{u}_{1}^{3}
$$

as applied before [Nielsen, 2006] to include progressive wave streaming in practical sand transport formulae.

\subsection{Effects of a Mean Pressure Gradient on Current and Stress}

[37] In reality, the boundary layer may also be affected by a mean pressure gradient, related to return current, undertow or effects of wave transformation on a sloping beach. This mean pressure gradient is not included in the simulations (and parameterizations) of section 4.2. We explore the influence of a mean pressure gradient on the mean current and stress components with the numerical model. Based on CASE 4: Van Doorn, with a mean pressure gradient of $0.2 \mathrm{~Pa} / \mathrm{m}$, we define three additional cases: with respectively a strongly increased positive mean pressure gradient, a zero mean, and a strong negative mean pressure gradient. The results are shown in Figure 10. Figure 10e for $U_{0}$ shows that the mean pressure gradients have large effects on both magnitude and shape of the $U_{0}$ profile inside the wave boundary layer. Not only the extreme cases, but also the simulation with zero mean pressure gradient show significant differences with the validation case. Figures 10a-10d show the current related shear stress and the various contributions to it, see equation (19). The waveshape contribution (Figure 10d) decreases with increasing pressure gradient, which is according expectation: a negative mean current reduces the difference between on- and offshore turbulence beneath the velocityskewed wave. The contribution of the pressure gradient (Figure 10c) is substantial: in the original validation case 4, with only a small return current, the contribution from the pressure gradient at the bed is already $1 / 3$ of the wave Reynolds stress (Figure 10b) at the bed. We can also observe that the wave Reynolds stress (Figure 10b) at the bed is not affected by an adapted mean pressure gradient. So also with strong undertow or shoaling effects, the wave Reynolds stress contribution to the mean bed shear stress can be modeled with equation (25).

[38] Estimates of realistic mean pressure gradients, that not only depend on the local situation, might be obtained 

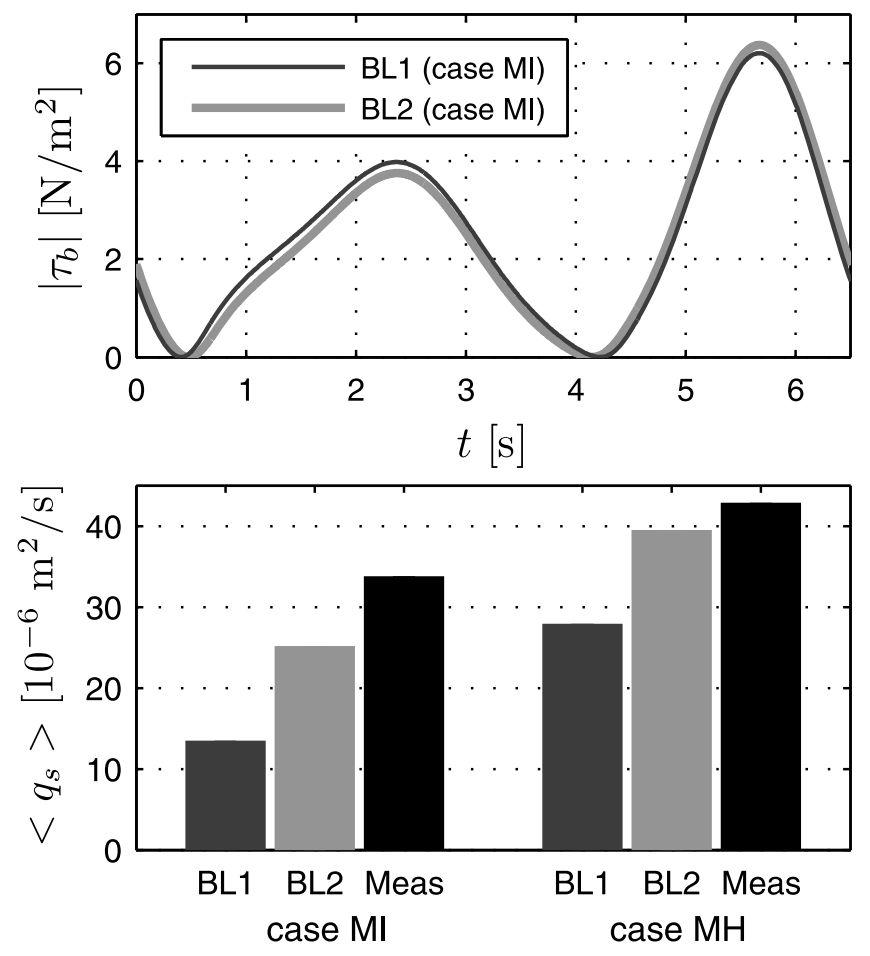

Figure 11. (top) Absolute bed shear stresses $\left|\tau_{\mathrm{b}}\right|$ as function of time for case MI of Dohmen-Janssen and Hanes [2002] computed both without (BL1) and with (BL2) progressive wave streaming. (bottom) Net sand transport rates $\left\langle q_{\mathrm{s}}\right\rangle$ for case MI and MH of Dohmen-Janssen and Hanes [2002] as determined from $\tau_{\mathrm{b}}(\mathrm{t})$ both without and with progressive wave streaming through a bed load transport formulae, compared with measured transport rates (Meas).

from wave properties, mass-fluxes and geometric information through undertow models. See also Zhang et al. [2011] who studied the wave boundary layer beneath shoaling and breaking waves, both generating mean pressure gradients, with a first order boundary layer model. The coupling to undertow models has not been tested here.

\section{Discussion}

[39] The main motive for this hydrodynamic study on wave boundary layer streaming is its potential influence on total sediment transport and nearshore morphology. Progressive wave streaming might explain the differences found in sand transport between tunnel and flume experiments. This is especially relevant, because most morphodynamic models use shear stress and transport formulations primarily based on tunnel experiments, and also tend to under predict onshore transport in accreting conditions [van Rijn et al., 2011]. To show the potential importance of progressive wave streaming for sediment transport, we apply the numerical model both with (BL2-version) and without free surface effects (BL1-version) for two conditions of the full scale flume experiments of Dohmen-Janssen and Hanes [2002] (MI and MH, both with grain size $d_{50}=0.24 \mathrm{~mm}$ ). Following the example of Gonzalez Rodriquez and Madsen [2011], we use the simulated time-dependent bed shear stress $\tau_{\mathrm{b}}(\mathrm{t})$ from both versions as input to a bed load sediment transport formula [Nielsen, 2006]:

$$
\begin{aligned}
& \frac{q_{s}(t)}{\sqrt{\left(\rho_{s} / \rho_{w}-1\right) g d_{50}^{3}}} \\
& \quad=\left\{\begin{array}{cc}
12[|\theta(t)|-0.05] \sqrt{|\theta(t)|} \frac{\theta(t)}{|\theta(t)|} & \text { for }|\theta(t)|>0.05 \\
0 & \text { for }|\theta(t)| \leq 0.05
\end{array}\right\}
\end{aligned}
$$

where $q_{\mathrm{s}}(\mathrm{t})$ and $\theta(\mathrm{t})$ are the time dependent sediment transport and Shields parameter respectively. The latter is computed from the model results for $\tau_{\mathrm{b}}(\mathrm{t})$ through:

$$
\theta(t)=\frac{\tau_{b}(t)}{\left(\rho_{s}-\rho_{w}\right) g d_{50}}
$$

To account for the higher roughness of the mobile bed, a bed roughness height $k_{\mathrm{N}}$ (model input) is used of the order of the maximum sheet flow layer thickness in these experiments $\left(k_{N}=20 D_{50}\right)$. Figure 11 shows results for $\tau_{\mathrm{b}}(\mathrm{t})$ and net transport rate $\left\langle q_{\mathrm{s}}\right\rangle$ from BL1 and BL2. The predicted $\left\langle q_{\mathrm{s}}\right\rangle$ increases with $40 \%$ in case $\mathrm{MH}$ and even $100 \%$ in case MI. So in the latter case, the contribution of progressive wave streaming to onshore transport is of the same order of magnitude as the contribution of velocity-skewness. In both cases, the measured $\left\langle q_{\mathrm{s}}\right\rangle$ is approached the best with progressive wave streaming included. Note that the numerical framework of the present model, shown to have some important advantages over the analytical approach concerning the hydrodynamics (see 3.4), also allows to investigate the role of streaming for fine sands, with much more sand in suspension. The question whether streaming is the full explanation of the differences in transport found in tunnel and flume will be discussed both for medium and fine sized sands in a future article, including a systematic data-model comparison involving all available large scale flume data.

[40] Although the test cases 1 to 4 are represented by the model reasonably well, they still show sometimes small differences between the measured and computed mean and unsteady flow near the bed. The question could therefore be raised whether these inaccuracies may form a serious shortcoming of the model when applied to sediment transport predictions. What is the deviation in predicted sediment transport these errors might introduce and how does this compare to the effects of progressive wave streaming we pointed at before? To get an impression hereof, we study the influence of inaccuracies in mean and unsteady flow on the third-order velocity moment $\left\langle u^{3}\right\rangle$. We do this for CASE 4 , for which near the bed $(0-5 \mathrm{~mm})$ the negative streaming was somewhat overpredicted and the phases of the harmonic components were underpredicted, the latter explained by the model's underestimation of the friction. We study $\left\langle u^{3}\right\rangle$ because in this region very close to the bed, it is reasonable to assume that $\tau_{\mathrm{b}}(\mathrm{t}) \sim|u(t)| u(t)$ and $q_{\mathrm{s}}(\mathrm{t}) \sim \tau_{\mathrm{b}}(t) u(t) \sim u(t)^{3}$ (at least for medium-sized sand, neglecting phase-lags of suspended sediment) [see Bailard, 1981; Ribberink and Al-Salem, 1994]. Figure 12 shows $\left\langle u^{3}\right\rangle$ computed from the experimental data and as computed by the model (BL2). Next, $\left\langle u^{3}\right\rangle$ has also been computed from a simulation without progressive wave streaming (BL1), and also again from the BL2 model but now with the computed mean 


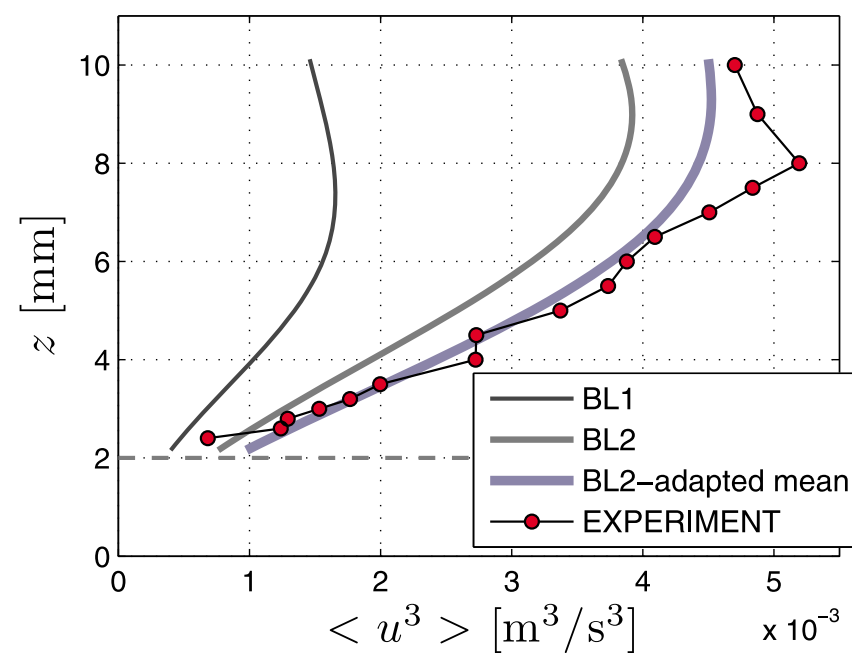

Figure 12. Third order velocity moment $\left\langle u^{3}\right\rangle$ as function of $z$, computed from the EXPERIMENT of case 4: Van Doorn; from results of simulations without (BL1) and with (BL2) progressive wave streaming; and from the BL2 model results with the computed mean velocity replaced by an approximation of the measured mean $(-0.0025 \mathrm{~m} / \mathrm{s})$.

velocity near the bed $(0-10 \mathrm{~mm})$ replaced by an approximation of the measured mean current $(-0.0025 \mathrm{~m} / \mathrm{s})$. In this way, possible differences between the first and the last computation can only be caused by inaccuracies in the simulated unsteady velocities. Figure 12 shows that the influence of unsteady flow inaccuracies on $\left\langle u^{3}\right\rangle$ is very small compared to steady flow inaccuracies, and the latter are much smaller than deviations introduced by neglecting progressive wave streaming (BL1). This underlines the primary importance of a good streaming prediction for sediment transport prediction in this case. At the same time, the present model performance in prediction of the near-bed unsteady flow seems to be sufficient.

[41] Concerning the validity of the model assumptions it should be noted that the results in section 4.2 have been obtained using Stokes theory to determine the waveshape. Seaward of the surf zone, where waves are predominantly velocity skewed with limited nonlinearity and accelerationskewness is nearly absent [Ruessink et al., 2009], this approximation is valid and the presented results can be applied. Note that the model itself is very well able to deal with the effects of larger nonlinearity and accelerationskewness on the boundary layer, as shown in section 3. So with a more advanced predictor of the waveshape, the model can also be applied in more shallow water and the surf zone. However, note that there also turbulence effects of (especially plunging) wave breakers may start to effect the boundary layer flow [Fredsøe et al., 2003; Scott et al., 2009].

[42] Finally, preliminary simulations with the present model including sediment and buoyancy-effects show a slight influence of suspended sediment on streaming, especially for fine sediment, most likely related to turbulence damping by density stratification. This asks for re-validation of the model on measured velocities above mobile beds when the contribution of progressive wave streaming to transport rates will be studied in more detail. Also here, reference is made to a future article which is focused on sediment transport prediction with the BL1 and BL2 models.

\section{Conclusion}

[43] A numerical boundary layer model has been developed to investigate the net current and shear stress in the bottom boundary layer as determined by waveshape effects and free surface effects. The latter have been taken into account by inclusion of advection of momentum and turbulence properties into the $1 \mathrm{DV}$-RANS model formulations and $k$ - $\varepsilon$ turbulence closure.

[44] The model has been validated with good agreement on a selection of experimental cases with different types of wave boundary layer flow. This fills a gap in literature on comparison of numerical models with measured mean wave boundary layer currents. The validation showed that both streaming processes, waveshape streaming and progressive wave streaming, need to be considered to reproduce the measurements. Besides, the turbulence memory in the model's $(\mathrm{k}-\varepsilon)$ turbulence closure and the presence of more harmonic velocity components contributes significantly to improved reproductions compared to earlier analytical modeling of streaming, e.g., the accurate reproduction of observed offshore current beneath acceleration-skewed waves where earlier analytical models failed.

[45] Subsequently, the model has been used to investigate the changing balance between offshore waveshape streaming and onshore progressive wave streaming for varying wave and bed conditions (section 4.2), by studying their contribution to the non-dimensional streaming velocity $U_{0} c / \hat{u}_{1}^{2}$ in the parameter space spanned by relative water depth $k h$ and roughness parameter $A / k_{\mathrm{N}}$. At relative deep water (large $k h$ ) the streaming is completely determined by the free surface effect. For decreasing relative water depth $(\mathrm{kh})$, the normalized progressive wave streaming stays nearly constant, but the importance of waveshape effect relative to the free surface effect increases. The effect of bed roughness is less distinct. For increasing relative bed roughness (decreasing $A / k_{\mathrm{N}}$ ), we found slightly stronger onshore progressive wave streaming. These model results have been parameterized in an expression for the streaming velocities at the top of the boundary layer as function of $k h$ and $A / k_{\mathrm{N}}$, see equation (23). The model results for the contribution of progressive wave streaming to the normalized mean bed shear stress do not show a roughness dependency and give a numerical confirmation of earlier analytical estimates hereof for sinusoidal waves, which are shown to apply also when a strong pressure gradient is present (section 4.3).

[46] Other insights obtained during this study are that the maximum offshore current resulting from velocity-skewness takes place on a lower level in the bottom boundary layer than the maximum onshore current from the progressive wave streaming. Therefore, layers with positive and negative shear $\left(\partial U_{0} / \partial z\right)$ can generally be observed in the mean current profile when both mechanisms are active. Next, the effect from acceleration-skewness is basically the same as the effect from velocity-skewness: a difference in turbulence properties during on- and offshore movement results in an offshore mean current. However, the acceleration-skewness effect is smaller and the level of the maximum offshore current is closer to the bed. 
[47] An exploration of the potential importance of the model results for sediment transport modeling is given in section 5, showing that increased bed shear stress due to progressive wave streaming leads to larger predicted sediment transport under waves, better matching the data. It is finally concluded that the validated numerical model provides a modeling framework for follow-up research on the question whether progressive wave streaming is the full explanation of the different sediment transport rates found in tunnel and flume experiments.

\section{Appendix A: Numerical Solution Method}

[48] The equations (1), (4) and (5) for momentum, turbulent kinetic energy and dissipation, are rewritten using (9) and (10) and discretized on a non-equidistant grid with staggered definition of the flow parameters: horizontal velocity and pressure are defined in the cell center, vertical velocity and turbulence properties at the cell interfaces. Every time step the three balance equations are solved consecutively: at first the new velocity field is computed, subsequently the new turbulence properties are determined using the newly obtained velocity field. The momentum balance is solved in two steps: first a new velocity is predicted from the first order terms (semi-implicit diffusion term), second the predicted velocity is used in the discretization of the nonlinear terms (vertical advection: first order upwind). The solution method above can result in a time step dependent numerical contribution to the waveaveraged current, caused by slight phase shifts between the various components of discretized terms. However, this error can never be larger than the numerical error from the discretization of the horizontal advective term without a predictor:

$$
\left.u \frac{\partial u}{\partial x}\right|_{k} \Rightarrow-\left.\frac{u}{c} \frac{\partial u}{\partial t}\right|_{k} \Rightarrow-\frac{u_{k}^{n}}{c} \frac{u_{k}^{n+1}-u_{k}^{n}}{\Delta t}
$$

(with $k$ the vertical level and $n$ the time step number). An analytical estimation of this error for a sinusoidal wave gives:

$$
\begin{aligned}
\int_{t=0}^{T}\left(-\frac{u^{n}}{c} \frac{\partial u^{n+1 / 2}}{\partial t}\right) d t & =\int_{t=0}^{T}\left\{-\hat{u}^{2} k \sin (\omega t-k x)\right. \\
& \left.\cos \left(\omega t-k x+\frac{\omega \Delta t}{2}\right)\right\} d t \\
& =T \frac{\hat{u}^{2} k}{2} \sin \left(\frac{\omega \Delta t}{2}\right)
\end{aligned}
$$

This indicates that (for reasonable values of $\Delta t$ ) the maximum error depends linearly on the time step. A time step criterium can be determined from equation (A2) and the requirement that the numerical contribution should be at least two orders smaller than the progressive wave streaming estimated with the expression of Longuet-Higgins [1958]. This would yield:

$$
\frac{\pi^{2} \Delta t}{T} \leq 0.01
$$

Representative model settings are (for simulations with the BL2-free model version): a time step of 1/1000 times the wave period, a simulation length of 100 waves and a grid of 150 layers exponentially divided over 1.2 times the estimated boundary layer thickness, leading to simulation durations of around $3 \mathrm{~min}$ that allow for systematic exploration of the parameter domain.

[49] As a check, it may be noted that the BL2-free model version perfectly reproduces the analytical solution of Longuet-Higgins [1958] for streaming under progressive sinusoidal waves when run with constant viscosity and the numerical results of Holmedal and Myrhaug [2009, Figure 7] when run with $\mathrm{k}-\varepsilon$ closure.

\section{Appendix B: Shape Expression}

[50] Equation (19) has been derived from the momentum balance (1) with the following steps:

[51] 1) Averaging over the wave period:

$$
\frac{\partial \overline{u w}}{\partial z}=-\frac{1}{\rho} \frac{\partial \bar{p}}{\partial x}+\frac{\partial}{\partial z}\left\{\overline{\left(v+v_{t}\right) \frac{\partial u}{\partial z}}\right\}
$$

[52] 2) Integration over $z$ :

$$
\overline{u w}=-\frac{1}{\rho} \frac{\partial \bar{p}}{\partial x} z+C_{1}+\overline{\left(v+v_{t}\right) \frac{\partial u}{\partial z}}
$$

[53] 3) Choice of integration constants such that all typical boundary layer terms are zero outside the boundary layer; no shear stress at the upper boundary $(z=h)$ :

$$
\left(\overline{u w}-\overline{u w}_{\infty}\right)=-\frac{1}{\rho} \frac{\partial \bar{p}}{\partial x}(z-h)+\overline{\left(v+v_{t}\right) \frac{\partial u}{\partial z}}
$$

[54] 4) Decomposition of turbulent viscosity and velocity into a period-averaged (overbar) and wave related (tilde) part and rearrangement of terms to express the mean current as a result of all other contributions:

$$
\left(v+\bar{v}_{t}\right) \frac{\partial \bar{u}}{\partial z}=\left(\overline{u w}-\overline{u w}_{\infty}\right)+\frac{1}{\rho} \frac{\partial \bar{p}}{\partial x}(z-h)-\overline{\widetilde{v}_{t}} \frac{\partial \widetilde{u}}{\partial z}
$$

with $\infty$ denoting the edge of the boundary layer.

[55] Acknowledgments. The first author thankfully acknowledges Dominic van der A (University of Aberdeen, UK), Suleyman Naqshband (University of Twente, NL), Alan Davies (Bangor University, UK), Martijn Henriquez (Delft University of Technology, NL) and Bas Borsje (University of Twente, NL) for data provision, contribution to the model validation and valuable discussion and comments. We also thank the (associate) editor and reviewers for their help to improve the manuscript.

\section{References}

Bailard, J. A. (1981), An energetics total load sediment transport model for a plane sloping beach, J. Geophys. Res., 86(C11), 10,938-10,954, doi:10.1029/JC086iC11p10938.

Campbell, L. J., T. O’Donoghue, and J. S. Ribberink (2007), Wave boundary layer velocities in oscillatory sheet flow, in Proceedings of 30th International Conference on Coastal Engineering, edited by J. McKee Smith, pp. 2207-2219, World Sci., San Diego, Calif.

Cavallaro, L., P. Scandura, and E. Foti (2011), Turbulence-induced steady streaming in an oscillating boundary layer: On the reliability of 
turbulence closure models, Coastal Eng., 58(4), 290-304, doi:10.1016/j. coastaleng.2010.10.001

Conley, D. C., S. Falchetti, I. P. Lohmann, and M. Brocchini (2008), The effects of flow stratification by non-cohesive sediment on transport in high-energy wave-driven flows, J. Fluid Mech., 610, 43-67, doi: $10.1017 /$ S0022112008002565.

Davies, A. G. (1980), Field observations of the threshold of sand motion in a transitional wave boundary layer, Coastal Eng., 4, 23-46, doi:10.1016/ 0378-3839(80)90004-6.

Davies, A. G., and Z. Li (1997), Modelling sediment transport beneath regular symmetrical and asymmetrical waves above a plane bed, Cont. Shelf Res., 17(5), 555-582, doi:10.1016/S0278-4343(96)00048-9.

Davies, A. G., and C. Villaret (1999), Eulerian drift induced by progressive waves above rippled and very rough beds, J. Geophys. Res., 104(C1), 1465-1488, doi:10.1029/1998JC900016.

Dohmen-Janssen, C. M., and D. M. Hanes (2002), Sheet flow dynamics under monochromatic nonbreaking waves, J. Geophys. Res., 107(C10), 3149, doi:10.1029/2001JC001045.

Fredsøe, J., and R. Deigaard (1992), Mechanics of Coastal Sediment Transport, Adv. Ser. on Ocean Eng., vol. 3, World Sci., Singapore.

Fredsøe, J., B. M. Sumer, A. Kozakiewicz, L. H. C. Chua, and R. Deigaard (2003), Effect of externally generated turbulence on wave boundary layer, Coastal Eng., 49, 155-183, doi:10.1016/S0378-3839(03)00032-2.

Fuhrman, D. R., J. Fredsøe, and B. M. Sumer (2009a), Bed slope effects on turbulent wave boundary layers: 1 . Model validation and quantification of rough-turbulent results, J. Geophys. Res., 114, C03024, doi:10.1029/ 2008JC005045.

Fuhrman, D. R., J. Fredsøe, and B. M. Sumer (2009b), Bed slope effects on turbulent wave boundary layers: 2 . Comparison with skewness, asymmetry, and other effects, J. Geophys. Res., 114, C03025, doi:10.1029/ 2008JC005053.

Gonzalez Rodriquez, D. (2009), Wave boundary layer hydrodynamics and cross-shore sediment transport in the surf zone, $\mathrm{PhD}$ thesis, Mass. Inst. of Tech., Cambridge, Mass.

Gonzalez Rodriquez, D., and O. S. Madsen (2011), Prediction of net bedload transport rates obtained in oscillating water tunnels and applicability to real surf zone waves, in Proceedings of 32nd International Conference on Coastal Engineering, edited by J. McKee Smith and P. Lynett, pp. 1-11, CERC, Shanghai, China.

Hassan, W. N. M., and J. S. Ribberink (2010), Modelling of sand transport under wave-generated sheet flows with a RANS diffusion model, Coastal Eng., 57(1), 19-29, doi:10.1016/j.coastaleng.2009.08.009.

Henderson, S. M., J. S. Allen, and P. A. Newberger (2004), Nearshore sandbar migration predicted by an eddy-diffusive boundary layer model, J. Geophys. Res., 109, C06024, doi:10.1029/2003JC002137.

Hinze, J. O. (1975), Turbulence, 2nd ed., edited by B. J. Clark, McGrawHill, New York

Holmedal, L. E., and D. Myrhaug (2006), Boundary layer flow and net sediment transport beneath asymmetrical waves, Cont. Shelf Res., 26(2), 252-268, doi:10.1016/j.csr.2005.11.004.

Holmedal, L. E., and D. Myrhaug (2009), Wave-induced steady streaming, mass transport and net sediment transport in rough turbulent ocean bottom boundary layers, Cont. Shelf Res., 29(7), 911-926, doi:10.1016/ j.csr.2009.01.012

Hsu, T.-J., and D. M. Hanes (2004), Effects of wave shape on sheet flow sediment transport, J. Geophys. Res., 109, C05025, doi:10.1029/ 2003JC002075

Hsu, T.-J., S. Elgar, and R. T. Guza (2006), Wave-induced sediment transport and onshore sandbar migration, Coastal Eng., 53, 817-824, doi:10.1016/j.coastaleng.2006.04.003.

Jackson, P. S. (1981), On the displacement height in the logarithmic velocity profile, J. Fluid Mech., 111, 15-25, doi:10.1017/S0022112081002279.

Johns, B. (1970), On the mass transport induced by oscillatory flow in a turbulent boundary layer, J. Fluid Mech., 43, 177-185, doi:10.1017/ S0022112070002306.

Johns, B. (1977), Residual flow and boundary shear stress in the turbulent bottom layer beneath waves, J. Phys. Oceanogr., 7, 733-738, doi:10.1175/1520-0485(1977)007<0733:RFABSS $>2.0 . C O ; 2$.

Jonsson, I. G. (1966), Wave boundary layers and friction factors, in Proceedings of 10th conference on Coastal Engineering, pp. 127-148, Am. Soc. Civ. Eng., Tokyo.

Jonsson, I. G. (1980), A new approach to oscillatory rough turbulent boundary layers, Ocean Eng., 7, 109-152, doi:10.1016/0029-8018(80) 90034-7.

Justesen, P. (1988), Turbulent wave boundary layers, PhD thesis, Inst. of Hydrodyn. and Hydraulic Eng. ISVA, Tech. Univ. of Denmark, Lyngby, Denmark

Kamphuis, J. W. (1975), Friction factor under oscillatory waves, J. Wtrwy., Harb. Coast. Eng. Div., 101(2), 135-144.
Klopman, G. (1994), Vertical structure of the flow due to waves and current, Prog. Rep. H840.30, Delft Hydraulics, Delft, Netherlands.

Launder, B. E., and D. B. Spalding (1972), Mathematical Models of Turbulence, Academic, London.

Li, M., S. Pan, and B. A. O'Connor (2008), A two-phase numerical model for sediment transport prediction under oscillatory sheet flows, Coastal Eng., 55(12), 1159-1173, doi:10.1016/j.coastaleng.2008.05.003.

Longuet-Higgins, M. S. (1953), Mass transport in water waves, Philos. Trans. R. Soc. London, Ser. A, 245(903), 535-581, doi:10.1098/ rsta.1953.0006.

Longuet-Higgins, M. S. (1958), The mechanics of the boundary-layer near the bottom in a progressive wave, in Proceedings of 6th Conference on Coastal Engineering, pp. 184-193, Am. Soc. Civ. Eng., Berkeley, Calif.

Nielsen, P. (1992), Coastal Bottom Boundary Layers and Sediment Transport, Adv. Ser. on Ocean Eng., vol. 4, World Sci., River Edge, N. J.

Nielsen, P. (2006), Sheet flow sediment transport under waves with acceleration skewness and boundary layer streaming, Coastal Eng. 53(9), 749-758, doi:10.1016/j.coastaleng.2006.03.006.

O'Donoghue, T., and S. Wright (2004), Flow tunnel measurements of velocities and sand flux in oscillatory sheet flow for well-sorted and graded sands, Coastal Eng., 51(11-12), 1163-1184, doi:10.1016/j.coastaleng. 2004.08.001.

Ribberink, J. S., and A. A. Al-Salem (1994), Sediment transport in oscillatory boundary layers in cases of rippled beds and sheet flow, J. Geophys. Res., 99(C6), 12,707-12,727, doi:10.1029/94JC00380.

Ribberink, J. S., and A. A. Al-Salem (1995), Sheet flow and suspension of sand in oscillatory boundary layers, Coastal Eng., 25(3-4), 205-225, doi:10.1016/0378-3839(95)00003-T.

Ribberink, J. S., J. J. van der Werf, T. O’Donoghue, and W. N. M. Hassan (2008), Sand motion induced by oscillatory flows: Sheet flow and vortex ripples, J. Turbul., 9(20), 1-32, doi:10.1080/14685240802220009.

Rodi, W. (1984), Turbulence Models and Their Applications in Hydraulics: A State of the Art Review, 2nd ed., Ashgate, Delft, Netherlands.

Ruessink, B. G., T. J. J. van den Berg, and L. C. van Rijn (2009), Modeling sediment transport beneath skewed asymmetric waves above a plane bed, J. Geophys. Res., 114, C11021, doi:10.1029/2009JC005416.

Schretlen, J. L. M., J. S. Ribberink, and T. O’Donoghue (2011), Boundary layer flow and sand transport, in Proceedings of 32 nd International Conference on Coastal Engineering, edited by J. McKee Smith and P. Lynett, pp. 1-14, CERC, Shanghai, China.

Scott, N. V., T.-J. Hsu, and D. Cox (2009), Steep wave, turbulence, and sediment concentration statistics beneath a breaking wave field and their implications for sediment transport, Cont. Shelf Res., 29(20), 2303-2317, doi:10.1016/j.csr.2009.09.008.

Sleath, J. F. A. (1987), Turbulent oscillatory flow over rough beds, J. Fluid Mech., 182, 369, doi:10.1017/S0022112087002374.

Swart, D. H. (1974), Offshore sediment transport and equilibrium beach profiles, $\mathrm{PhD}$ dissertation, Delft Univ. of Tech., Delft, Netherlands.

Trowbridge, J., and O. S. Madsen (1984a), Turbulent wave boundary layers: 1. Model formulation and first-order solution, J. Geophys. Res., 89(C5), 7989-7997, doi:10.1029/JC089iC05p07989.

Trowbridge, J., and O. S. Madsen (1984b), Turbulent wave boundary layers: 2. Second-order theory and mass transport, J. Geophys. Res., 89(C5), 7999-8007, doi:10.1029/JC089iC05p07999.

Trowbridge, J., and D. Young (1989), Sand transport by unbroken water waves under sheet flow conditions, J. Geophys. Res., 94(C8), 10,971-10,991, doi:10.1029/JC094iC08p10971.

Van der A, D. A., T. O'Donoghue, A. G. Davies, and J. S. Ribberink (2011), Experimental study of the turbulent boundary layer in accelerationskewed oscillatory flow, J. Fluid Mech., 684, 251-283, doi:10.1017/ jfm.2011.300.

Van Doorn, T. (1981), Experimental investigation of near-bottom velocities in water waves with and without a current, Rep. M1423, Delft Hydraulics Lab., Delft, Netherlands.

van Rijn, L. C. (2007), Unified view of sediment transport by currents and waves. I: Initiation of motion, bed roughness, and bed-load transport, J. Hydraul. Eng., 133(6), 649, doi:10.1061/(ASCE)0733-9429(2007) 133:6(649).

van Rijn, L. C., P. K. Tonnon, and D. J. R. Walstra (2011), Numerical modelling of erosion and accretion of plane sloping beaches at different scales, Coastal Eng., 58(7), 637-655, doi:10.1016/j.coastaleng.2011.01.009.

Yu, X., T.-J. Hsu, and D. M. Hanes (2010), Sediment transport under wave groups: Relative importance between nonlinear waveshape and nonlinear boundary layer streaming, J. Geophys. Res., 115, C02013, doi:10.1029/ 2009JC005348

Zhang, C., J. Zheng, Y. Wang, and Z. Demirbilek (2011), Modeling wavecurrent bottom boundary layers beneath shoaling and breaking waves, Geo Mar. Lett., 31(3), 189-201, doi:10.1007/s00367-010-0224-9. 